\title{
Design of Nanostructured Functional Coatings by Using Wet-Chemistry Methods
}

\author{
Pedro J. Rivero ${ }^{1,2, *}$, Jose A. Garcia ${ }^{1}$ (D), Iban Quintana ${ }^{3}$ and Rafael Rodriguez ${ }^{1,2}$ \\ 1 Materials Engineering Laboratory, Department of Mechanical, Energy and Materials Engineering, \\ Public University of Navarre, Campus Arrosadía S/N, 31006 Pamplona, Spain; \\ joseantonio.garcia@unavarra.es (J.A.G.); rafael.rodriguez@unavarra.es (R.R.) \\ 2 Institute for Advanced Materials (INAMAT), Public University of Navarre, Campus Arrosadía S/N, \\ 31006 Pamplona, Spain \\ 3 IK4-TEKNIKER, C/Iñaki Goenaga 5, 20600 Eibar, Spain; iban.quintana@tekniker.es \\ * Correspondence: pedrojose.rivero@unavarra.es
}

Received: 22 December 2017; Accepted: 11 February 2018; Published: 14 February 2018

\begin{abstract}
This review reports the implementation of novel nanostructured functional coatings by using different surface engineering techniques based on wet chemistry. In the first section, the theoretical fundaments of three techniques such as sol-gel process, layer-by-layer (LbL) assembly and electrospinning will be briefly described. In the second section, selected applications in different potential fields will be presented gathering relevant properties such as superhydrophobicity, biocide behavior or applications in the field of optical fiber sensors.
\end{abstract}

Keywords: wet-chemistry methods; nanofabrication techniques; nanostructured functional coatings

\section{Introduction}

Surface engineering was defined, in the late eighties, as "the application of traditional and innovative surface technologies to engineering components and materials in order to produce a composite material with properties unattainable in either the base or surface material" [1]. For many years, the main purpose of surface engineering techniques was the protection of materials against corrosion and tribological problems. Two main strategies have been employed to reach this goal: surface modification techniques and coatings. The first strategy provides incremental changes that affect the material up to some characteristic depth. Treatments such as surface hardening, shot or laser peening, thermochemical treatments or the different techniques of ion implantation modify the first layers of a material in ranges that go from tenths of microns to several millimeters. The resulting properties are very dependent of those of the substrate and the main advantage is that there is not an abrupt discontinuity between the treated zone and the untreated substrate but a smooth transition between them. On the other hand, the coating strategy is more radical: a new material is deposited on the former surface and the resulting properties are basically those of the coating (paintings, electrolytic coatings, CVD (chemical vapor deposition) or PVD (physical vapor deposition) layers). This option makes possible a much broader choice of solution, although the main drawbacks are related to problems of adherence and compatibility that can arise in the interlayer coating-substrate.

The emergence of nanotechnology as a new paradigm in the field of materials science and engineering led to new approaches in the search of materials with new properties, based on the " $3 S^{\text {" }}$ of their components: size, shape, and structure. The case of new developments in PVD hard coatings is a good example of the potentiality of the nanotechnological approach. For instance, the hardness of a material (or a coating) increases as the grain size diminishes according to the Hall-Petch equation, reaching a maximum around $10 \mathrm{~nm}$, when the sliding of the grain boundaries becomes relevant enough to decrease this hardness beyond this critical size [2]. A similar pattern can be observed in the case of 
multilayered PVD coatings: by reducing the thickness of the bi-period, it is possible to obtain coatings with a better hardness (and other mechanical properties) than the constituents separately. Once again, a maximum in hardness is observed around 5-10 nm, reaching values labeled as "superhardness" [3]. The development of nanostructures for protective coatings has proven to be successful against wear and corrosion resistance, and due to this, a great deal of work has been developed in the last 25 years, in a higher number in comparison with the case of bulk materials. The main reason behind this major advance is that, unlike the case of bulk materials synthesis, coating deposition processes are highly versatile and naturally provide very small crystalline grain sizes or can incorporate nanoparticles in a tailored way without the difficulties for controlling phase distribution and homogeneity of grain size that we meet in the processing of bulk materials. It is easier to create a nanostructure in a quasi-2D material than in a 3D one [4].

Protection of materials was the first, but not the only goal of surface engineering. Since the emergence of microelectronic techniques, many treatment and coating technologies have been specifically developed or adapted to create micro (and now, nano) structures able to perform precise functions in electronics, optoelectronics or photonics. Moreover, the functionalization of surfaces is the area that experiences a faster growth within surface engineering. Technological challenges such as selective optical transmissivity and reflectivity, hydrophobicity, bacteriostaticity or different cases of sensoric can be addressed by means of surface modification techniques and/or coatings that create nanopatterns or homogenous dispersions of nanoparticles or nanoprecipitates.

Accordingly, a survey of recent publications shows that the number of published papers related to both nanotechnology and coatings has increased during the last two decades from 1995 to 2015, as can be clearly observed in Figure 1, opening the door for the fabrication of a new generation of nanomaterials.

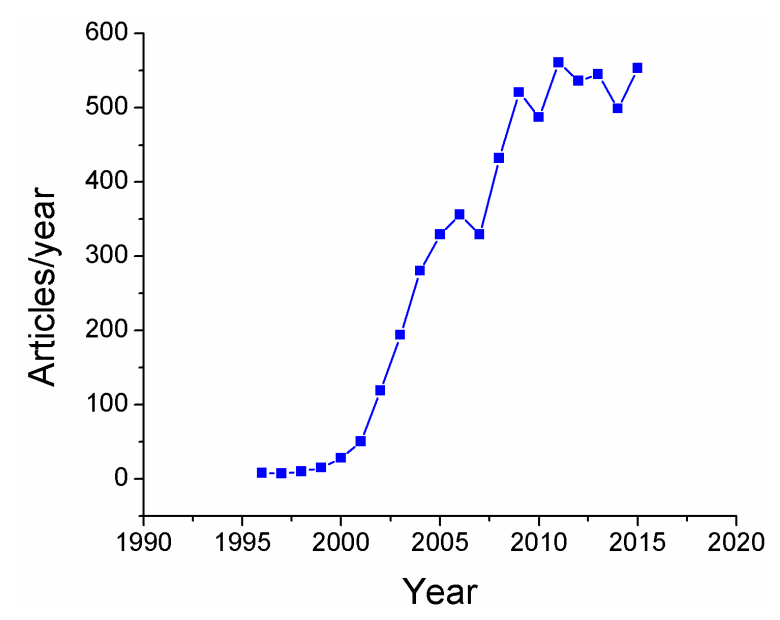

Figure 1. Number of published documents (article, conference paper, review or book chapter) with the words "Nanotechnology" and "Coatings" in their title, abstract or keywords (source: Scopus database).

This review is focused on three main applications of nanostructured functional coatings deposited by wet-chemistry methods: superhydrophobic, antibacterial and sensorized coatings. In many cases, wet-chemistry has clear practical advantages in comparison with the more expensive high vacuum physical techniques as PVD or ion implantation or other optical-based strategies such as interference nanolithography or pulsed laser texturing. To illustrate this point, a brief revision of the most promising wet-chemistry techniques is presented in Section 2, in order to show their potentiality for the selected applications which will be commented on in Section 3. 


\subsection{Nanofabrication Techniques for the Design of Functional Coatings}

In this section, the theoretical and fundamental concepts related to deposition technologies for developing nanostructured thin-films will be briefly described. Firstly, three different wet-chemistry technologies such as layer-by-layer (LbL) assembly, dip-coating sol-gel process and electrospinning will be presented.

\subsection{The Layer-by-Layer ( $L b L)$ Assembly}

The layer-by-layer $(\mathrm{LbL})$ assembly consists of the alternate immersion of the substrate (mostly of glassy, polymeric or metallic nature) into aqueous polyelectrolyte solutions with opposite electric charge, known as polycations and polyanions, respectively, the electrostatic attraction being the main force to adsorb them onto a surface [5]. It is important to note that both polyanions and polycations overlap each other at the molecular level, making possible the fabrication of a homogeneous coating at the nanoscale level. The resultant combination of a cationic monolayer (polycation) and an anionic monolayer (polyanion) is called a bilayer [6,7]. The resultant composition and thickness of an individual bilayer can be controlled by adjusting several deposition parameters such as molar concentration, $\mathrm{pH}$, temperature, immersion time and ionic strength of the polyelectrolyte dipping solutions [8-10]. In addition, the LbL assembly is considered a versatile, highly reproducible and easily scalable technique, making possible the development of coatings on substrates of almost any size or shape. A great benefit of this nanodeposition technique is that a wide variety of substances (fluorescent dyes, nanoparticles or quantum dots) can be perfectly entrapped in the charged polyelectrolytes with the aim to obtain a multilayer structure [11-17]. As an example, Figure 2 shows the high versatility of this nanofabrication technique, being possible to fabricate multicolored LbL films (orange, green or violet) as a function of the gradual incorporation of silver nanoparticles with a desired coloration $[18,19]$.
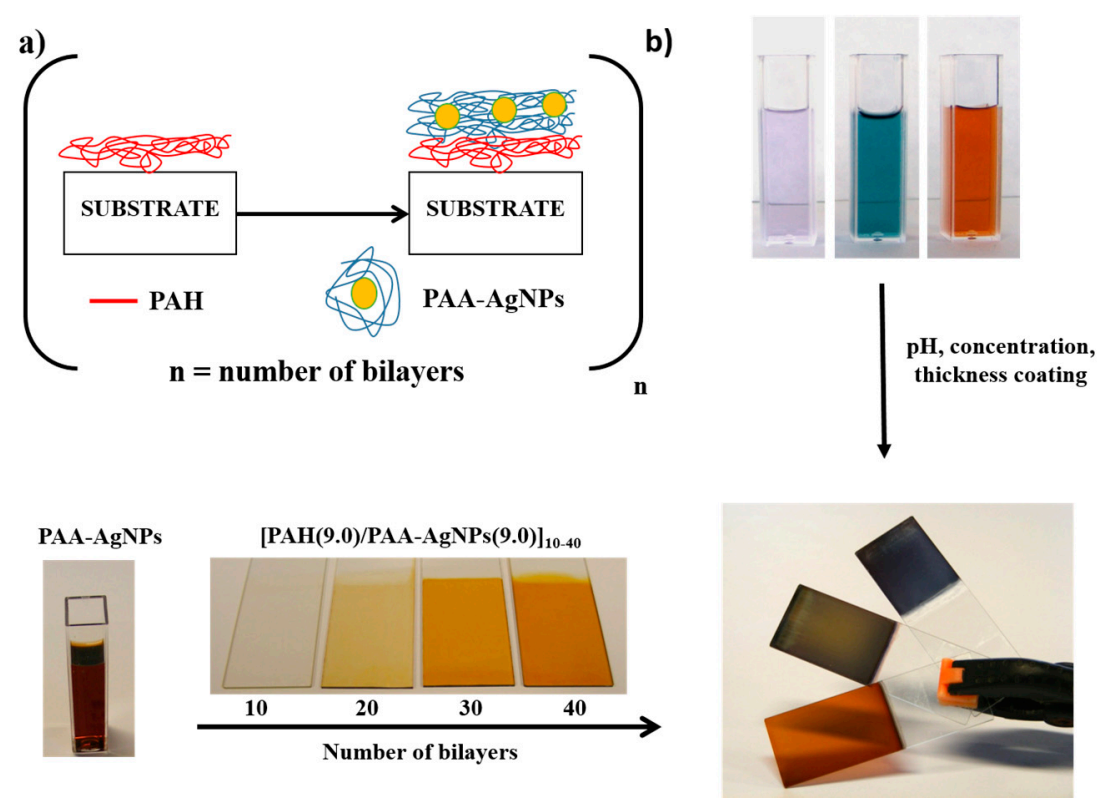

Figure 2. (a) Schematic representation of the layer-by-layer (LbL) technique by using poly(allylaminehydrochloride) (PAH) as a polycation and poly(acrylic acid, sodium salt) (PAA) as a polyanion which is acting as a capping agent of the silver nanoparticles (PAA-AgNPs) and aspect of the orange colored LbL coatings as a function of the number of bilayers. (b) Multicolored LbL coatings (orange, green or violet) as a function of previous synthesized PAA-AgNPs and the $\mathrm{pH}$, concentration and thickness coating. Reproduced from [19] with permission; Copyright Springer 2013. 


\subsection{The Sol-Gel Dip-Coating Technology}

The sol-gel process is one of the fastest-growing fields of contemporary chemistry owing to its high simplicity and versatility, being suitable to be used on a wide variety of substrates. This chemical process is based on a synthetic route for preparing inorganic as well as inorganic-organic materials (known as hybrid materials) with high purity [20]. All the chemical reactions (hydrolysis, condensation and polycondensation) follow the same evolution from a sol, a colloidal suspension of solid particles in a liquid, to produce a gel, a substance that contains a continuous solid skeleton enclosing a continuous liquid phase [21-23]. An important advantage is that the resultant sol-gel reactions do not employ extreme reaction conditions because these reactions take place at room or low temperature, a moderate temperature being necessary for a final curing step of the gel. In addition, several fabrication parameters such as the type of metal alkoxyde precursor, $\mathrm{pH}$, nature and concentration of the catalyst, $\mathrm{H}_{2} \mathrm{O}: \mathrm{Si}$ molar ratio, the type of co-solvent, temperature, method and extension of drying, the presence of doping substances or the pulling up speed must be perfectly controlled in order to provide a powerful, simple, flexible and low-cost processing technique [24,25]. Once the sol-gel precursor has been prepared and aged for a specific period of time, the substrate is immersed into it by using the dip-coating technique. After a fixed period of time, it is pulled out from the gel by using a determined extracting speed. Then, the substrate is dried and some additional processing steps can be included such as a heat treatment at controlled conditions of temperature and pressure. These steps can be repeated until the coating has acquired the desired thickness.

Figure 3 shows a schematic representation for the design of a hybrid sol-gel coating composed of metallic silver nanoparticles (AgNPs). As can be appreciated in Figure 3a, a hybrid coating is fabricated as a function of an adequate selection of both inorganic alkoxyde precursor and organic precursor, respectively. Then, the in situ synthesis process for obtaining the resultant AgNPs on this hybrid sol-gel coating is performed by using a chemical reduction method. In this step, the sol-gel hybrid matrix is immersed in a source of silver ions (silver nitrate, $\mathrm{AgNO}_{3}$ ) and a further reduction step of the silver ions to the resultant metallic nanoparticles is performed by immersion in a specific reducing agent solution (dimethylamino borane, DMAB) [26]. Finally, the difference between a sol-gel hybrid matrix without AgNPs (totally transparent) and sol-gel hybrid coatings composed of AgNPs (orange color) can be clearly observed when a higher number of Loading/Reduction (L/R) cycles are performed. This change in coloration clearly indicates that a progressive incorporation of AgNPs into the sol-gel hybrid coating is obtained.

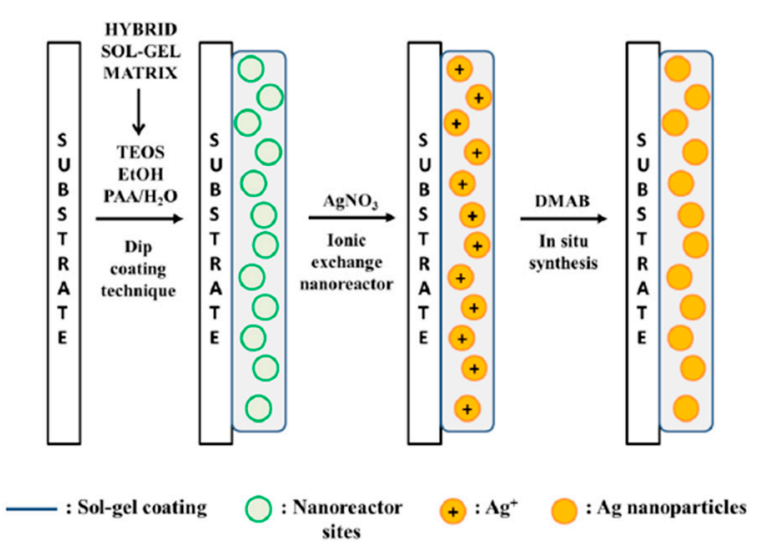

(a)

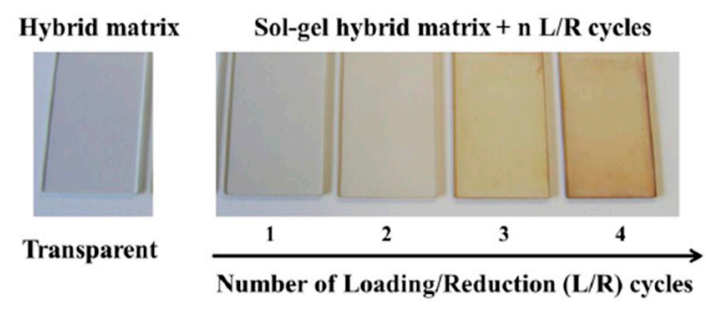

(b)

Figure 3. (a) Schematic representation for the design of hybrid sol-gel coatings composed of silver nanoparticles (AgNPs) by using a Loading/Reduction chemical process. (b) Aspect of the resultant sol-gel hybrid coatings before the synthesis of AgNPs (totally transparent) and after the incorporation of the AgNPs by in situ synthesis process from light yellow to orange coloration. Reproduced from [26] with permission; Copyright Springer 2011. 


\subsection{Electrospinning Process}

The electrospinning technique is a good alternative to fabricate materials with a high surface area due to the possibility of producing nanostructured ultra-thin fibers denoted as electrospun nanofibers (ENFs) from a wide range of materials (polymers, composites and ceramics) onto any type of surface with arbitrary geometry [27]. In the last 15 years, the number of scientific papers related to this technique has shown an exponential growth due to the numerous intrinsic advantages of this nanofabrication technique such as high simplicity, versatility, effectiveness, low-cost and quickness of the fabrication process. Due to all these advantages, it makes possible its implementation in a wide range of industrial applications [28-32]. In this process, the diameter and density of the ENFs are influenced by critical fabrication parameters such as viscosity of the precursor solution, applied voltage, the flow rate and the distance between collector/needle. In addition, the fabricated nanofibers show additional advantages such as a good control over the resultant diameter, highly porous surface and flexibility for a further chemical/physical functionalization [33,34]. Besides, an important aspect to remark is that the resultant fiber mats have a specific area of two orders of magnitude larger than the specific area corresponding to continuous flat films [35].

In this technique, the resultant nanofibers are fabricated by applying a high-voltage field to the precursor solution with respect to a ground electrode. A schematic representation of the electrospinning process is summarized in Figure 4 where the precursor solution is held at the end of a conductive capillary tube (needle), which is subjected to an electric field that induces charge on the liquid surface. As the solution travels in air, due to the electric forces, the solvent is evaporated during the flight of the fibers and finally, the ENFs are deposited on the ground screen collector or the substrate to be coated (see Figure 4a). In this case, an optical fiber core has been coated with ENFs, as can be observed in Figure $4 \mathrm{~b}$, the design of novel optical fiber sensors being able to monitor physical or chemical parameters (relative humidity, $\mathrm{pH}$, gases or human breathing) [36]. As will be commented upon in the following section related to functional applications of nanostructured coatings, these optical fiber sensors based on ENFs show a very fast response time, being a critical parameter in the field of sensors market [37].

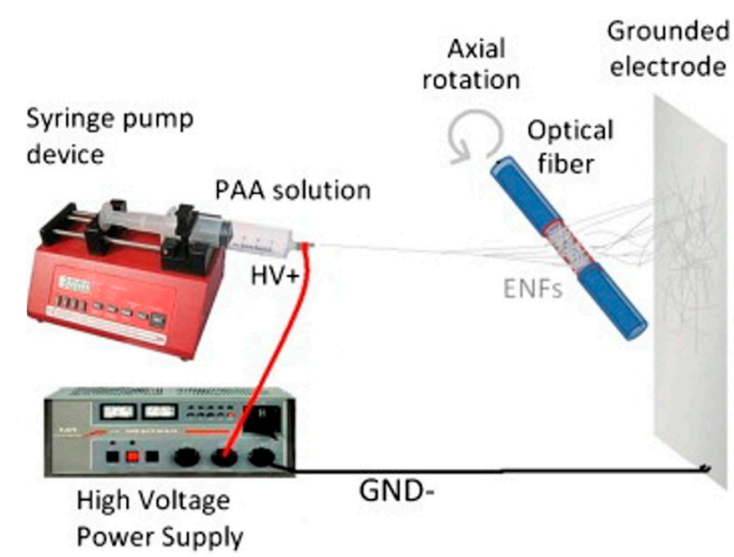

(a)

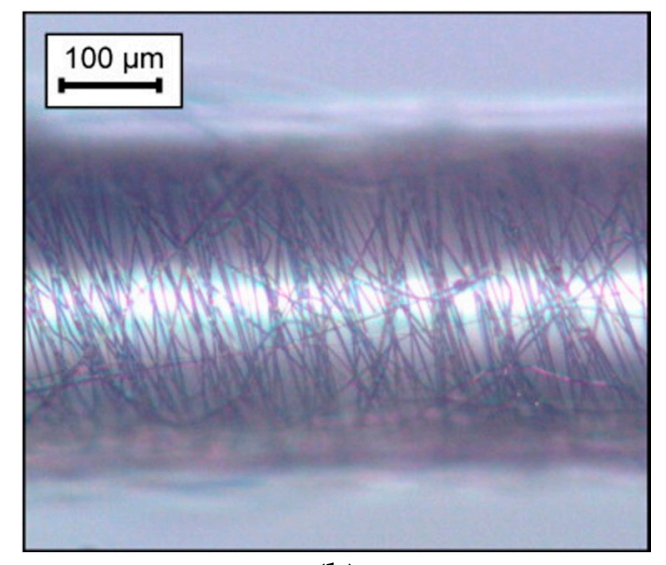

(b)

Figure 4. (a) Schematic representation of the electrospinning fabrication process where the fiber fragment is placed perpendicularly to the syringe direction in order to collect the ENFs. (b) Optical fiber core coated with the ENFs after the fabrication process. Reproduced from [36] with permission; Copyright Elsevier 2013.

Once these three wet chemical coating techniques have been briefly commented upon, the main processing advantages and disadvantages of using each one of these three key technologies as a function of the equipment, productivity and resultant structure as well as the desired thickness of the nanocoatings has been summarized in Table 1. 
Table 1. Wet-chemical coating techniques evaluated in this work (layer-by-layer assembly, sol-gel dip-coating method and electrospinning process, respectively): advantages, disadvantages and final structure.

\begin{tabular}{|c|c|c|c|}
\hline Technique & Advantages & Disadvantages & Final Structure \\
\hline LbL assembly & $\begin{array}{l}\text { A simple and versatile technique; } \\
\text { Different substrates can be coated (metals, plastics, ceramics or even } \\
\text { semiconductors) with different shapes and sizes; } \\
\text { A repetitive and highly reproducible method; } \\
\text { An easily scalable method, though time-consuming, for multilayer } \\
\text { fabrication and industrial applications; } \\
\text { No requirement of highly sophisticated materials or apparatus; } \\
\text { It is carried out at room conditions; } \\
\text { A good alternative to encapsulate a wide variety of chemical } \\
\text { substances (indicators, nanoparticles, luminescent materials, } \\
\text { quantum dots). }\end{array}$ & $\begin{array}{l}\text { Only valid for water-soluble } \\
\text { molecules (polyelectrolytes); } \\
\text { Fabrication of soft coatings; } \\
\text { Fabrication process can be long for thicker coatings as a } \\
\text { function of the immersion time in the polyelectrolyte } \\
\text { solutions and the final number of bilayers. }\end{array}$ & $\begin{array}{l}\text { The final thickness and the surface } \\
\text { properties can be tuned in a precise manner } \\
\text { as function of the number of bilayers, } \\
\text { concentration of the solution, } \mathrm{pH} \text { and the } \\
\text { ionic strength of the polyelectrolytes. }\end{array}$ \\
\hline Sol-gel dip-coating technique & $\begin{array}{l}\text { No sophisticated equipment (dip-coater); } \\
\text { A good alternative to entrap molecules, enzymes or antibodies; } \\
\text { Low-cost, flexible, simple and non-hazardous method for preparing } \\
\text { coatings with controllable composition and microstructure; } \\
\text { Excellent adhesion to the substrate; } \\
\text { Possibility of obtaining a high variety of sol-gel derived materials as } \\
\text { a function of the initial metal-alkoxyde precursor. } \\
\text { Design of hybrid coatings makes possible to combine organic and } \\
\text { inorganic properties; } \\
\text { Fabrication of hard coatings with a high resistance to thermal or } \\
\text { photo-chemical degradation. }\end{array}$ & $\begin{array}{l}\text { The lack of a precise film thickness control up to } 200 \mathrm{~nm} \text {; } \\
\text { Long aging time for the preparation of the sol-gel } \\
\text { solution precursors; } \\
\text { Curing step needs a moderate or high temperature to } \\
\text { form a denser cross-linked coating. }\end{array}$ & $\begin{array}{l}\text { The pulling up speed determines the } \\
\text { resultant thickness coating; } \\
\text { Depending on sol-gel processing parameters } \\
\text { such as molecular precursor, water to silane } \\
\text { ratio, nature of the catalyst, sol aging time } \\
\text { and temperature; } \\
\text { Acid-catalyzed reactions promote the } \\
\text { formation of linear polymers; } \\
\text { Basic-catalyzed reactions promote the } \\
\text { formation of highly cross-linked polymers. }\end{array}$ \\
\hline
\end{tabular}




\section{Nanostructured Functional Applications}

\subsection{Superhydrophobic Surfaces}

One of the hot topics in academic science and industrial technology is the ability to control the wettability of a solid surface for potential practical applications. In fact, nowadays, two well-known concepts such as hydrophilicity and hydrophobicity are the most published topics in scientific papers reported in bibliographies. In this sense, the design of bioinspired surfaces with special surface wettability has attracted the attention of the scientific community because a high number of biological organisms can be found which exhibit a special surface wettability such as the antifogging functionality of mosquito eyes, antireflection of superhydrophobic cicada wings or self-cleaning property of lotus leaves, among others [38]. According to this, an emerging effort is gradually being focused on the development of novel coatings which simulate the structure-function relationship of these natural materials.

A clear example is the lotus effect related to a specific water repellent plant (Nelumbo nucifera) which leads to an ideally wonderful superhydrophobic effect with supreme self-cleaning properties thanks to the rough structure of the lotus leaves (a template with hills and valleys), making possible a reduced contact area with water. The concept of superhydrophobia can be defined as those surfaces which prevent water contact angles higher than $150^{\circ}$, which is also commonly known as the artificial lotus effect. The appropriate texturing and roughening of the resultant surfaces on the nano and microscale are used to obtain these extreme wetting characteristics $[39,40]$. In order to obtain these specific superhydrophobic surfaces is necessary to combine two variables such as low surface free energy and a high degree of roughness. Once these two key experimental factors are perfectly controlled, applications of relevant importance related to the design of superhydrophobic surfaces can be found in fields as diverse as functional textiles or high-performance anticorrosive coatings, these being the main areas of study in this superhydrophobic surface section.

In order to obtain water repellency behavior to textiles, it is necessary to have a strict control over the topography of the fabric by using chemical methods with the aim of modifying the surface of the fibers and leaving the fabric permeable to air and water vapor [41]. Among all the different chemical methods, sol-gel technology is considered one of the most conventional methods to be used in the textile industry due to its easy processing, acceptable thermal conditions (low curing temperature) and its ability to provide uniform thin films. Most of the approaches found in the literature for obtaining a low surface energy are based on the use of metal alkoxydes with hydrophobic functional groups. An interesting approach for imparting water and oil repellency is presented by Gao et al. [42] where the combination of both silica sol and hexadecyltrimethoxysilane (HDTMS) have been used to impart an extremely high hydrophobicity to cotton and polyester fabrics, respectively. The high hydrophobicity of the treated fabrics is due to the presence of the hydrophobic HDTMS in the outer surface combined with an increase in the roughness by using alkaline hydrolysis conditions of the silica sol. In addition, this sol-gel chemical synthetic method has the additional advantages of being an environmentally friendly and cost-effective procedure, showing resistance to hydrolysis of multiple washing cycles. Another interesting approach based on an alkaline hydrolysis is presented by Mazrouei-Sebdani and Khoddani [43]. In this work, the fabrication of "lotus-type" polyester fabric is presented by combining two major requirements such as low surface energy and a high degree of roughness. In order to obtain this dual effect, firstly an alkaline hydrolysis has been performed for improving surface roughening. In addition, secondly, a further fluorocarbon layer has been deposited with the aim of generating low surface energy.

Another interesting work based on the co-hydrolysis and co-condensation of two different silane precursors for obtaining hybrid silica sol-gel coatings is presented by Wang et al. [44]. It has been clearly demonstrated that the use of non-hydrolyzable functional groups in the organic silane such as alkyl, fluorinated alky or phenyl shows an important influence on the fabric surface wettability. 
Finally, in order to increase the washing durability of the superhydrophobic coating, a third type of silane based on an epoxy group has been successfully incorporated.

Alternative works $[45,46]$ for the design of superhydrophobic polyester fabrics are based on the surface functionalization of $\mathrm{SiO}_{2}$ nanoparticles with the aim to obtain fluoropolymer $/ \mathrm{SiO}_{2}$ nanocomposites. In these works, firstly vinyl silica hydrosols are synthesized by one-step sol-gel process by using vinyl trimethoxy silane as metal alkoxyde precursor and ammonium hydroxide as a catalyst. In addition, secondly, an emulsion polymerization has been used for the synthesis of a fluorinated acrylic polymer/silica. The presence of silica nanoparticles makes possible a rough surface structure, whereas the low surface energy is provided by fluoropolymer.

Another novel work based on the incorporation of metallic nanoparticles for textile finishing with the aim of increasing the roughness surface is presented by Berendjchi et al. [47]. In this work, nanoparticles of copper are incorporated into silica sols in order to fabricate surfaces with dual properties of being antibacterial and superhydrophobic, respectively. First of all, it is well known that copper has been used as an excellent antibacterial agent for centuries and the desired antibacterial properties of copper can be considerably improved with its reduction size in the nanometric scale. In addition, the presence of these $\mathrm{Cu}$ nanoparticles into silica sol enables a surface with a higher air trapping capability onto cotton fabrics. The experimental results indicate that the addition of $0.5 \%$ $(w / w) \mathrm{Cu}$ into silica produces a flocculation of colloidal silica nanoparticles and such agglomeration produces more grape-like clusters on the final surface. This specific morphology related to the combination of copper into silica sol shows a higher air trapping with a slightly better static contact angle (SWC) value $\left(155.9^{\circ}\right)$ in comparison with coatings treated with only an alkylsilane agent such as HDTMS without any metallic nanoparticles $\left(151.1^{\circ}\right)$. In this work, the surface morphology has been evaluated by scanning electron microscopy (SEM), while the surface roughness has been analyzed via the scanning probe microscope (SPM), respectively. In Figure 5, SEM and SPM micrographs of the untreated fabric, treated with the silica sol without nanoparticles and the sample with $\mathrm{Cu}$-doped silica are presented. First of all, the great difference in the resultant roughness between the untreated samples and the samples with silica can be clearly appreciated. In addition, the $\mathrm{Cu}$-doped treated samples shows valleys as can be observed in the SPM images. Finally, the sol-gel fabricated surfaces containing $\mathrm{Cu}$ nanoparticles displayed acceptable antibacterial properties against E. coli and S. aureus bacteria.

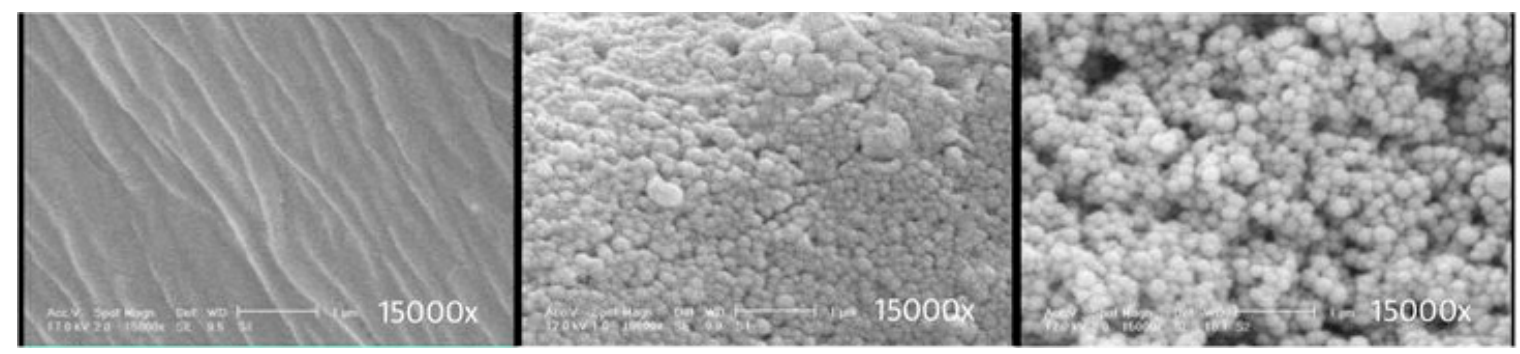

(a)

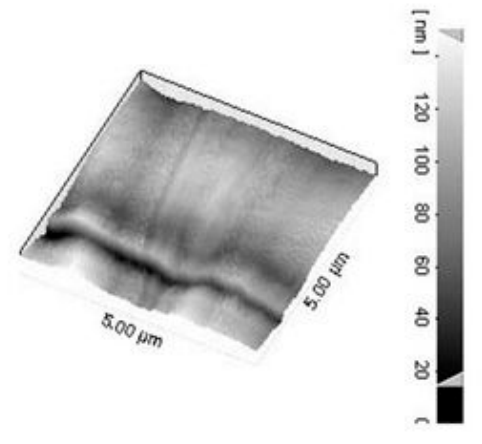

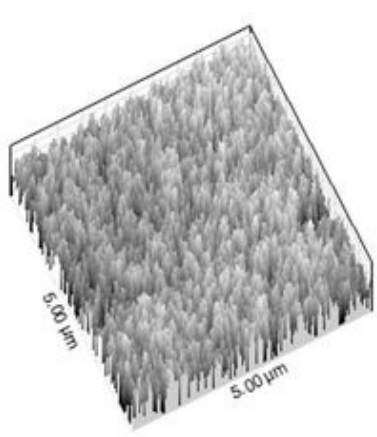

(b)
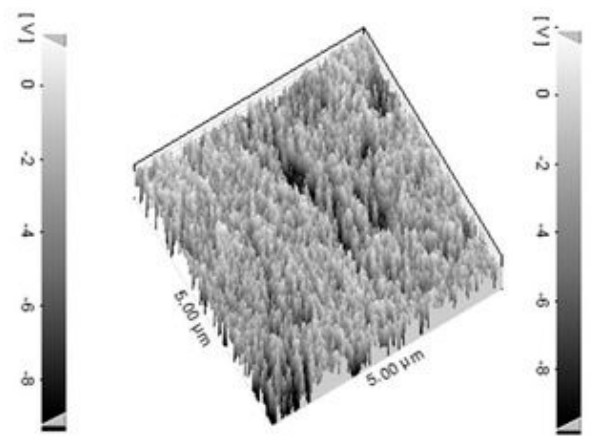

Figure 5. Cont. 


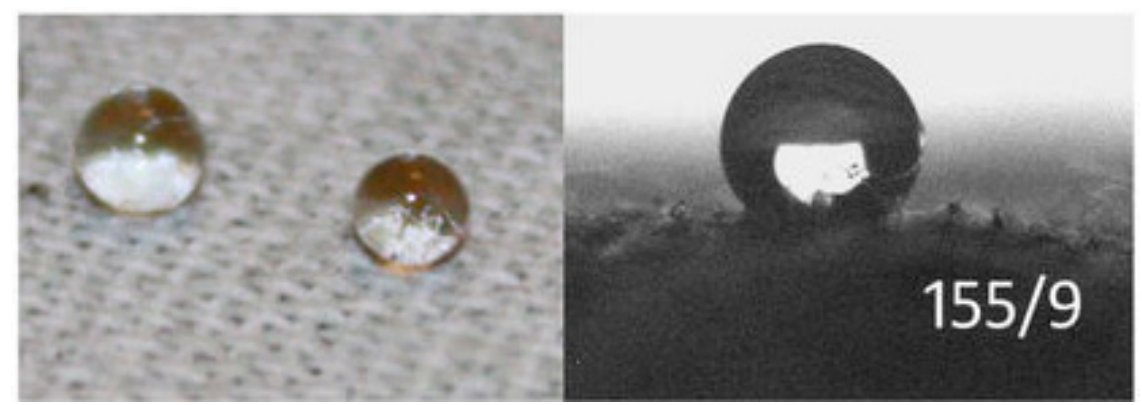

(c)

Figure 5. (a,b) SEM and SPM micrographs of fabricated surfaces: untreated (left), silica sol (middle) and $\mathrm{Cu}$-doped silica (right); (c) Water drops on surface fabricated by $0.5 \% \mathrm{Cu}$-doped silica sol and its contact angle value. Reproduced from [47] with permission; Copyright Springer 2011.

As has been previously commented upon, the fabrication of superhydrophobic surfaces can also be employed for corrosion protection of metals (aluminum, steel, copper or even magnesium). In this sense, sol-gel technology is one of the most suitable alternatives for corrosion protection pre-treatments due to its environmentally compliance and compatibility with organic paints which are used in most applications. In addition, the use of hybrid sol-gel matrices has a higher flexibility and versatility to accept different types of additives in comparison with the simple sol-gel matrices. These hybrid sol-gel matrices make possible the combination of the properties of the inorganic materials as well as the properties of organic [48-50]. Accordingly, the inorganic materials are used to enhance the durability, adhesion and scratch resistance of the coatings, whereas the organic materials in the resultant sol are used to improve the density of the films, reducing the possibility of cracking formation during the drying process. In this curing step, a highly cross-linked siloxane network is formed by thermally inducing self-condensation reactions, removing the hydrophilic hydroxide groups from the remaining silanol molecules and as a result, the formation of a denser thick film is obtained. A clear example is presented by Du et al. [51] where hybrid sol-gel coatings showed an enhancement of the mechanical properties such as hardness and abrasion resistance, being very important the curing step at elevated temperature in order to pass the adhesion test. Another interesting work related to an important increase in the hardness of the silica coatings as a function of the thermal treatment of the curing step is presented by Cairns et al. [52]. Another novel work for the preparation of sol-gel coatings with both superhydrophobicity and enhanced hardness is presented by Lakshmi et al. [53]. This work shows a simple method to fabricate hard superhydrophobic sol-gel nanocomposite coatings using hydrophilic silica nanoparticles. More specifically, silica particles of size 25-30 nm have been incorporated in a hybrid sol of nano-sized colloidal and silica methyltriethoxysilane (MTEOS). The resultant surface of the sol-gel coatings exhibited a highly porous structure with nanosize voids and randomly distributed micro size bumps, showing a water contact angle as high as $162.5^{\circ}$ with an excellent adhesion and pencil hardness. In a later work, Lakshmi et al. [54] reported the effect of size of silica nanoparticles on wettability and surface chemistry for the design of sol-gel superhydrophobic and oleophobic coatings with good self-cleaning properties, a thermal treatment being necessary to expel the trapped solvents. Another approach for the preparation of scratch-resistant superhydrophobic coatings by applying a multilayer approach including multiple sol-gel processes is presented by Taurino et al. [55].

Once the high versatility of the hybrid sol-gel matrices has been demonstrated, novel works can be found in the bibliography for the design of sol-gel coatings with high corrosion-resistant performance in corrosive environments. Liang et al. [56] reported a facile sol-gel method with tetra-ethylorthosilicate (TEOS) and vinyltriethoxysilane (VTEOS) as co-precursor for the fabrication of superhydrophobic surfaces on aluminum surfaces at room temperature. In this work, the experimental results obtained by polarization curves clearly indicate that the resultant superhydrophobic sol-gel hybrid coatings exhibit a higher corrosion resistance than the untreated aluminum because the 
corrosion potential is considerably shifted to the positive direction compared to the untreated aluminum. In addition, other potential factor related to the sol-gel technology is the high versatility for combining with other different processes such as micro-arc oxidation or hydrothermal method for obtaining superhydrophobic surfaces with an enhanced corrosion resistance [57,58].

However, other interesting alternatives for improving corrosion resistance are based on the incorporation of fluoroalkylsilane into the outer surface of the coatings in order to enhance the hydrophobic surface of the surface. A clear example was presented by $\mathrm{Yu}$ and $\mathrm{Xu}$ [59] where fluorinated organic-inorganic hybrid films were prepared by sol-gel process, and the results indicated that the outermost layer of the water-repellent film was associated with the presence of perfluoroalkyl groups. Caldarelli et al. [60] reported an optimized process for obtaining superhydrophobic copper surfaces by means of sol-gel technique. In this work, the resultant superhydrophobicity is associated with the combination of two factors, a peculiar alumina flower-like structure with submicrometric air pockets and the low surface energy of the fluorinated organic compound. Another approach is presented by Liu et al. [61] where the combination of $\mathrm{TiO}_{2}$ nanoparticles for increasing the surface roughness with fluoroalkylsilane for increasing the hydrophobic property of the surface is reported. The resultant water contact angle is around $150^{\circ}$, exhibiting an excellent corrosion resistance in chloride solution at room temperature. Isimjam et al. [62] have reported a similar approach where two different types of nanoparticles $\left(\mathrm{TiO}_{2}\right.$ and $\left.\mathrm{SiO}_{2}\right)$ have been successfully incorporated by using layer-by-layer assembly onto the steel substrate with the aim of obtaining micro and nanoscale binary structure with different surface roughness, and then the surfaces have been modified by the low free energy chemical PTES (perfluorodecyl-triethoxysilane). The resultant coatings showed a strong repulsive force to water droplets with a static contact angle of $165^{\circ}$ and a strong chemical stability to various solvents including $0.01 \% \mathrm{HCl}$.

Another novel work which proposed a multilayer sol-gel nanocoating onto aluminum alloys for the fabrication of new surfaces with dual properties of a high degree of hydrophobicity and corrosion resistance is presented by Maeztu et al. [63]. In this work, a combination of a hybrid matrix to host the corrosion inhibitor (graphene oxide, $\mathrm{GrO}_{x}$ ) with a simple sol-gel matrix to provide hydrophobic properties (fluorinated polymeric chains) is presented. The effect of a thermal treatment is analyzed in order to promote a denser thick film, and as a result an improvement in the resultant mechanical and hydrophobic properties is obtained. In addition, the thermally treated samples showed a better corrosion performance, which has been demonstrated by polarization curves and electrochemical impedance tests. Figure 6, represents the aspect of the water droplet after performing the multilayer sol-gel coating of the thermally treated sample. In addition, it has been corroborated that this curing step makes possible the fabrication of nanocoatings with a better hardness and hydrophobic behavior. Finally, the cyclic potentiodynamic curves in $3.5 \% \mathrm{NaCl}$ solution indicate that the combination of a corrosion inhibitor in the inner part of the coating $\left(\mathrm{GrO}_{x}\right)$ with the hydrophobic fluorine chains in the outer part of the coating makes possible the design of a novel multilayer structure with an improvement in the corrosion resistance. Two main conclusions have been obtained of the corrosion data. The first one is that an increase of the resultant thickness (from 1 to 6 dips) resulted in the shift of the pitting corrosion potential towards a more positive one. In addition, the second one is that the sol-gel hybrid coatings composed of $\mathrm{GrO}_{x}$ presented a better pitting corrosion resistance in comparison with the blank sol-gel hybrid coatings. 

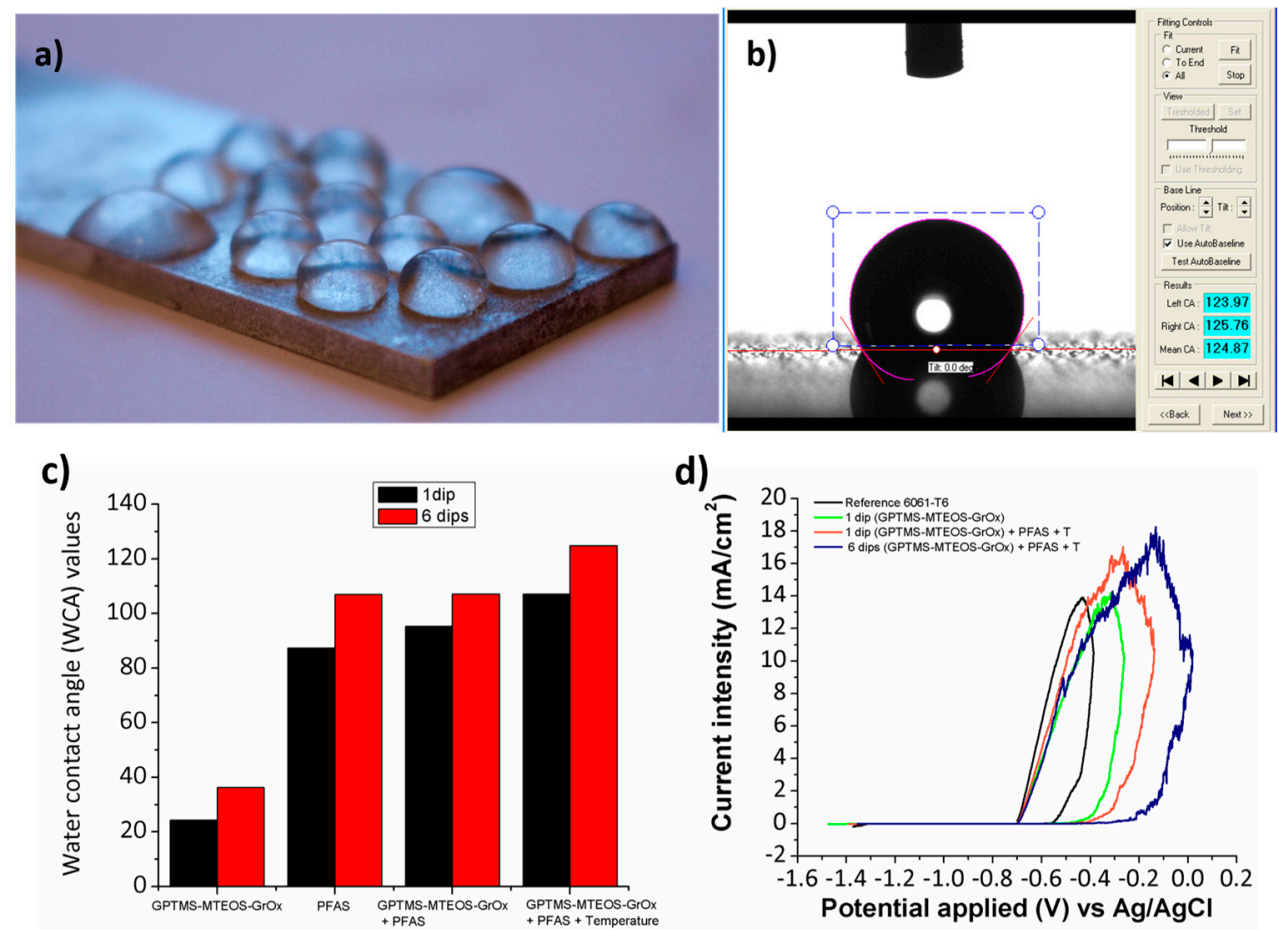

Figure 6. (a) Droplet of water onto aluminum substrate for sample of 6 dips of GPTMS-MTEOS and PFAS, respectively; (b) Contact angle value of the sample thermally treated; (c) evolution of the water contact angle value as a function of the number of dips and thermal treatment; (d) Cyclic polarization curves in 3.5\% $\mathrm{NaCl}$ solution for the different samples of study. Reproduced from [63] with permission; Copyright Elsevier 2017.

There are other interesting works based on the corrosion-protective properties of nanostructured sol-gel hybrid coatings to metallic alloys. In these works, the main idea is to combine the barrier effect of silica coatings with the corrosion inhibitor effect of different types of inorganic nanoparticles. Zheludkevich et al. [64] have reported that the presence of zirconia $\left(\mathrm{ZrO}_{2}\right)$ nanoparticles with an amorphous structure and a variable diameter (from 40 to $200 \mathrm{~nm}$ ) are used to improve corrosion protection, showing a pore blocking effect. Pepe et al. [65] evaluated the presence of cerium ions in silica sol-gel coatings and the results clearly indicated that there is an inhibition of the corrosion by cerium salts which migrate thorough the coating to the site of the attack and then react to passivate the site. Another work based on the development of silica coatings doped with $\mathrm{TiO}_{2}-\mathrm{CeO}_{2}$ nanoparticles is presented by Zaharescu et al. [66]. In this work, the binary powder plays a dual key role in the resultant hybrid inorganic-organic films. Firstly, it is used to increase the barrier properties due to the formation of a dense, crack-free and pore-free material. In addition, secondly, the cerium oxide from the powder plays an inhibiting role and hinders the corrosion process.

Another different approach is presented by Liang et al. [67] where a facile one-step method is presented to fabricate novel smart nanocontainers as key and efficient components for the development of self-healing coating with superhydrophobic surfaces. The synthetic chemical route for the fabrication of smart nanocontainers, $\mathrm{SiO}_{2}$-imidazoline nanocomposites $\left(\mathrm{SiO}_{2}\right.$-IMI) is based on Stober method by using a silica precursor (TEOS) and aqueous ammonium as a catalyst in the presence of an imidazoline derivative (HMID) as a corrosion inhibitor. The resultant morphology of the $\mathrm{SiO}_{2}$-IMI containers can be appreciated in TEM images, showing a nearly monodispersed spherical shape with uniform diameter of about $100 \mathrm{~nm}$. An important aspect is that during the corrosion process, the presence of corrosive species (chlorides, sulfates, oxygen) are prone to intrude into the coating, reach the surface and initiate the localized corrosion. According to this, sudden $\mathrm{pH}$ changes occur in the corrosive micro-regions of aluminum alloy because there is a decrease of the $\mathrm{pH}$ value in the micro-anodic 
regions due to the dissolution of the $\mathrm{Al}$ and subsequent hydrolysis of $\mathrm{Al}^{3+}$, whereas there is a local alkalization in the micro-cathodic regions. Due to this, the stimuli-responsive characteristics of the $\mathrm{SiO}_{2}$-IMI particles have been evaluated by using release experiments at three different $\mathrm{pH}$ values such as acidic ( $\mathrm{pH} 4.0)$, neutral ( $\mathrm{pH}$ 7.0) and alkaline ( $\mathrm{pH}$ 10.0) conditions, as can be observed in Figure 7. The experimental results clearly indicate that the release profiles of $\mathrm{HMID}$ from $\mathrm{SiO}_{2}$-IMI under acidic or alkaline conditions are totally different from those under the neutral conditions. At the end of the release experiment (4 days of exposition), nearly of 95\% embedded HMID has been released for acid conditions ( $\mathrm{pH} 4.0$ ), being slightly more elevated than under basic conditions ( $\mathrm{pH} 10.0$ ), whereas the neutral solution shows a negligible HMID release (less than $1.5 \%$ within $4 \mathrm{~h}$ of exposition and $17 \%$ after 4 days). In addition, two important ideas can be obtained from these experimental results. Firstly, a clear acid/alkali dual-stimuli pH-dependent behavior was observed for the synthesized $\mathrm{SiO}_{2}$-IMI nanoparticles. In addition, secondly, when the stronger acidity or alkalinity was applied, a faster release rate has been obtained. Once this special acid/alkali dual-stimuli accelerated release property has been demonstrated, these $\mathrm{SiO}_{2}$-IMI particles have been uniformly distributed into the hydrophobic $\mathrm{SiO}_{2}$ sol in order to construct "host-guest" feedback active coating $\left(\mathrm{SiO}_{2}-\mathrm{IMI} @ S H C\right)$ with a superhydrophobic surface onto the metallic aluminum substrate by using the dip-coating technique. These $\mathrm{SiO}_{2}$-IMI (guest component) have a great biocompatibility with the sol-gel (host) coatings, and once the localized corrosion occurs on the aluminum surface, $\mathrm{SiO}_{2}$-IMI can release HMID with the aim of forming a compact molecular film on the damaged surface, inhibiting the corrosion spread and executing a self-healing function.
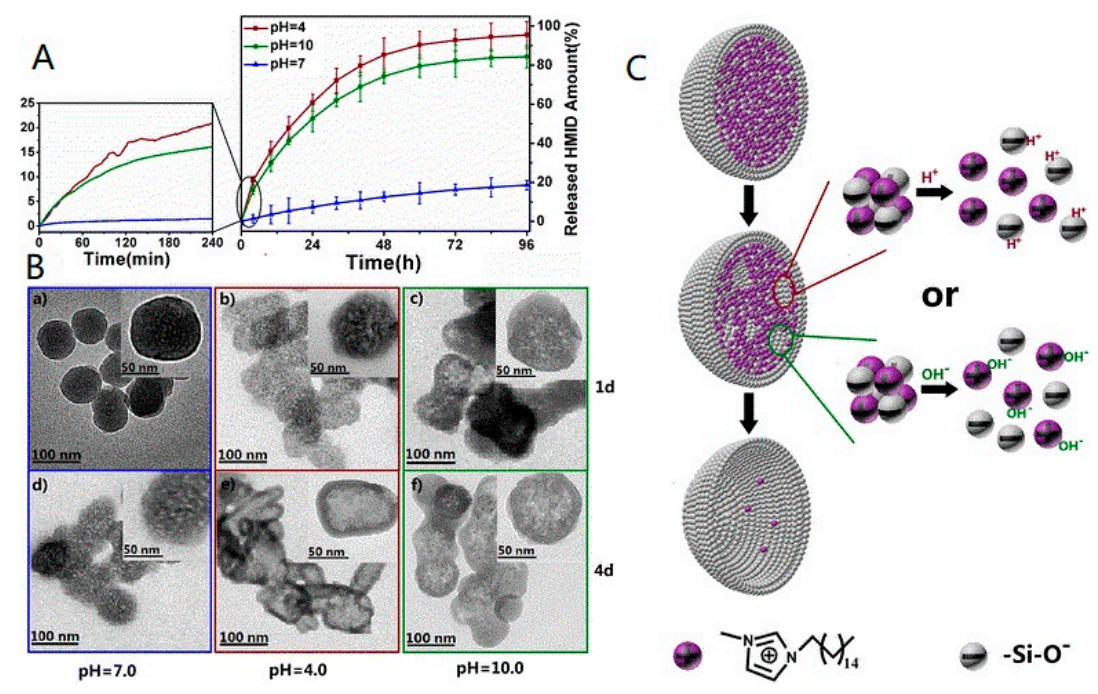

Figure 7. (A) Release profiles of $\mathrm{HMID}$ from $\mathrm{SiO}_{2}$-IMI at different $\mathrm{pH}$ values; (B) TEM images of the $\mathrm{SiO}_{2}$-IMI taken after being immersed in solution with different $\mathrm{pH}$ values $((\mathbf{a}, \mathbf{d}) \mathrm{pH}=7.0,(\mathbf{b}, \mathbf{e}) \mathrm{pH}=4.0$, and $(\mathbf{c}, \mathbf{f}) \mathrm{pH}=10.0)$ for $(\mathbf{a}-\mathbf{c}) 1$ day and $(\mathbf{d}-\mathbf{f}) 4$ days; $(\mathbf{C})$ The acid/alkali stimuli-accelerated release mode of $\mathrm{SiO}_{2}$-IMI. Reproduced from [67] with permission; Copyright Springer 2016.

Other novel works are focused on the use of assembled multilayer polyelectrolytes onto healing agents (corrosion inhibitors) by using layer-by-layer assembly which can be released on demand (external stimuli, $\mathrm{pH}$, light, chemical reactions) [68]. In this sense, the $\mathrm{pH}$-dependent self-healing of LbL deposited multilayer of weak and strong polyelectrolytes can be used as an effective anticorrosion protection system [69,70]. In addition, the development of superhydrophobic surfaces with self-healing is a very promising engineering approach. Li et al. [71] reported bioinspired self-healing superhydrophobic coatings. In this work, firstly a porous polymer coating that is rigidly flexible is fabricated, showing a micro and nanoscaled hierarchical structure. In addition, secondly, chemical vapor deposition (CVD) of a fluoroalkylsilane is performed, the resultant coatings being 
superhydrophobic due to the formation of a covalently attached fluoroalkylsilane layer. Once the top layer is scratched, the preserved healing agents can migrate to the coating surface under a slightly humid environment to heal the superhydrophobicity. A novel approach to the self-healing and recovery of damaged micro- and nanoscale topographic features in crushed polymer-based superhydrophobic coatings is presented by Manna and Lynn [72].

Finally, as can be commented in the nanofabrication techniques section, another approach for the design of superhydrophobic surfaces with corrosion protection is the electrospinning process. A clear example is presented by Radwan et al. [73] where a protective superhydrophobic PVDF-ZnO nanocomposite coating obtained by on-step electrospinning technique is prepared for aluminum against corrosion. The experimental results showed a WCA of 155 and a better corrosion protection efficiency for aluminum than electrospun PVDF samples without the presence of $\mathrm{ZnO}$ nanoparticles. In another recent work, Zhao et al. [74] reported superhydrophobic polyaniline(PANI)/ polystyrene (PS) micro/nanostructures for protecting carbon steel. The resultant coatings showed a water contact angle as high as $153^{\circ}$ with excellent anticorrosion properties with a corrosion protection efficiency of $99.48 \%$. Other approach based on the use of polystyrene is also presented by Zhao et al. [75] where a bilayer coating is prepared through a superposition method as a function of a topcoat composed of polystyrene (PS) and primer composed of polyaniline (PANI)/polymethyl methacrylate (PMMA). The experimental results indicate that the PANI-PMMA primer fabricated by electrospinning combined with PS topcoat fabricated by spray process showed the best corrosion protection, its protection efficiency being up to $99.95 \%$ after $720 \mathrm{~h}$ in $3 \% \mathrm{NaCl}$. In previous research articles, Zhao et al. [76,77] had reported the great anticorrosion protection of electrospun PANI/PMMA microfibers film due to its extraordinary compact structure.

It has been briefly commented that two different possibilities related to the implementation of superhydrophobic surfaces in the field of functional textiles as well as high-performance anticorrosion coatings; a summary of the different examples exposed in this work can be found in Table 2.

Table 2. Summary of the design of superhydrophobic or highly hydrophobic surfaces in the field of functional textiles and metallic substrates for the design of anticorrosive properties.

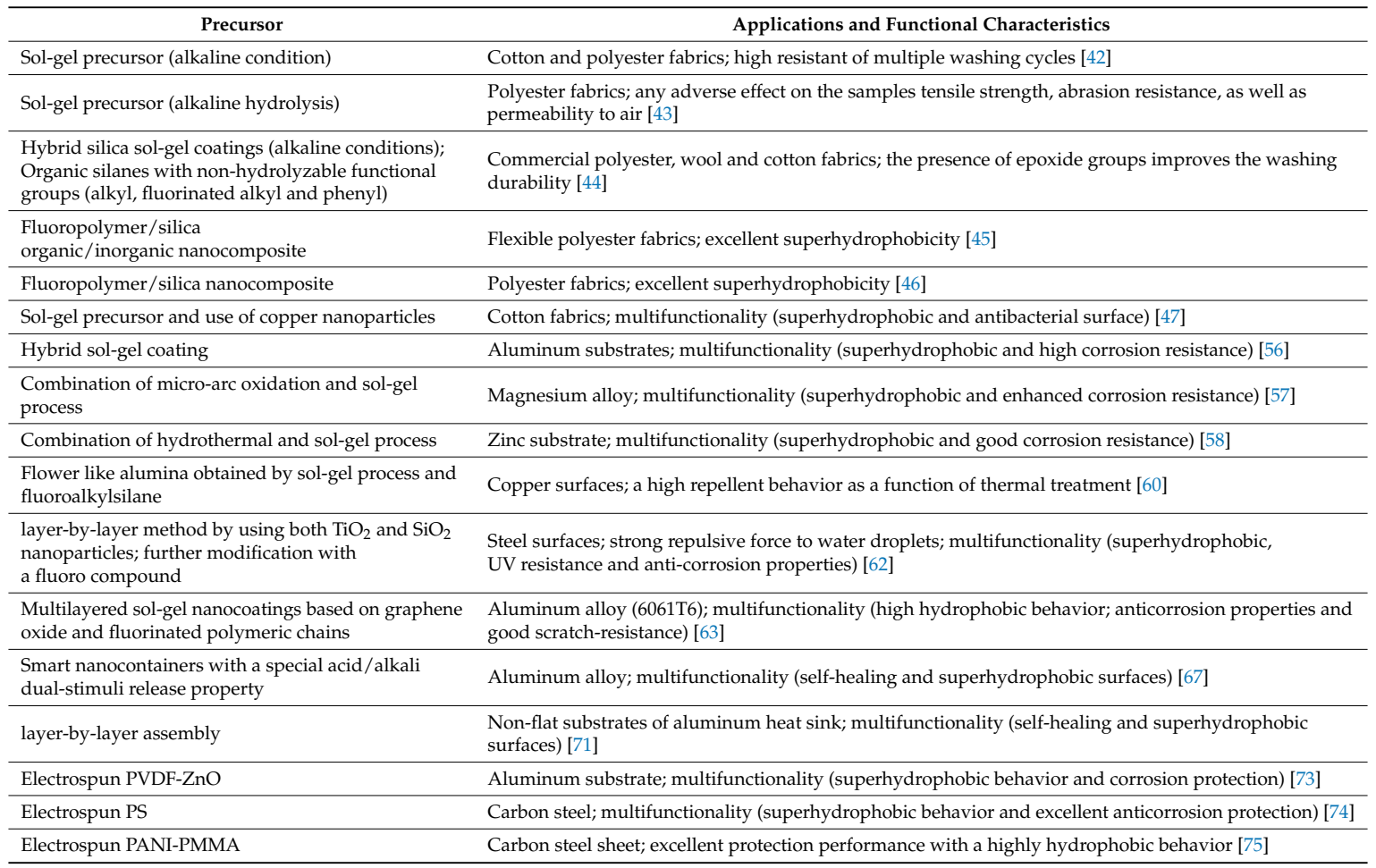




\subsection{Biocide Surface Treatments}

Nowadays multi-resistant bacteria that have emerged from the indiscriminate use of antibiotics are one of the most serious problems in healthcare. Bacteria biofilms can survive under deficient nutrient conditions, developing resistance to biocides. In this way, infections are the most frequent complications in hospitals with dramatic consequences. It has been estimated that around $80 \%$ of the infections in hospitals involve bacterial biofilms that have up to a higher resistance of 1000 times to antimicrobials than bacteria in the planktonic form. The use of antimicrobial surfaces can be an effective strategy to interrupt transmission of bacteria from materials to humans [78-81].

One of the best known antibacterial agents is silver which has been widely applied in biomedical applications due to its associated large surface area and a good release of its corresponding metallic cations. In addition, this chemical element shows the additional advantage of being successfully incorporated with a high versatility in different chemical wet methods (sol-gel, layer-by-layer, electrospinning). According to these synthetic processes, there are two main methodologies for incorporating silver nanoparticles (AgNPs) into the nanostructured thin-films. The first one is associated with a direct incorporation of the metallic nanoparticles during the fabrication process of the nanocoating, whereas the second one is based on in situ synthesis of AgNPs after performing the resultant nanocoating. A clear example of this second option related to the in situ synthesis by using the electrospinning process is presented by Rivero et al. [82]. In this work, PAA/cyclodextrin nanofibers have been electrospun onto the substrate, then these nanofibers have been thermally treated and finally, a chemical reduction process has been performed in order to promote the in situ synthesis of the AgNPs by using the dip-coating technique. In order to obtain the AgNPs, firstly the electrospun nanofibers have been immersed in a loading solution of silver nitrate $\left(\mathrm{AgNO}_{3}\right)$ with the aim of charging the nanofibers with Ag cations, and secondly, a reduction step with a reducing agent has been performed in order to reduce silver cations to metal nanoparticles. A TEM image of the in situ synthesis of the AgNPs loaded electrospun nanofibers with their specific antibacterial efficiency against a specific bacteriological culture of Lactobacillus plantarum can be observed in Figure 8 . More specifically, it is possible to see the photographs of a bare glass substrate (Figure 8a) and other samples coated with electrospun fibers loaded with silver nanoparticles (Figure $8 b$ ). In the reference sample, the bacterial growth happened in the whole agar slab and also under the glass, whereas in the silver loaded fibrous membrane coating no bacteria were found. The killing efficiency of these samples composed of electrospun nanofibers with AgNPs was higher than $99.99 \%$. It is important to remark that this same methodology related to the in situ synthesis of AgNPs can be extrapolated to other different wet-chemistry techniques such as the sol-gel process, showing a complete inhibition of the bacteria growth [26].
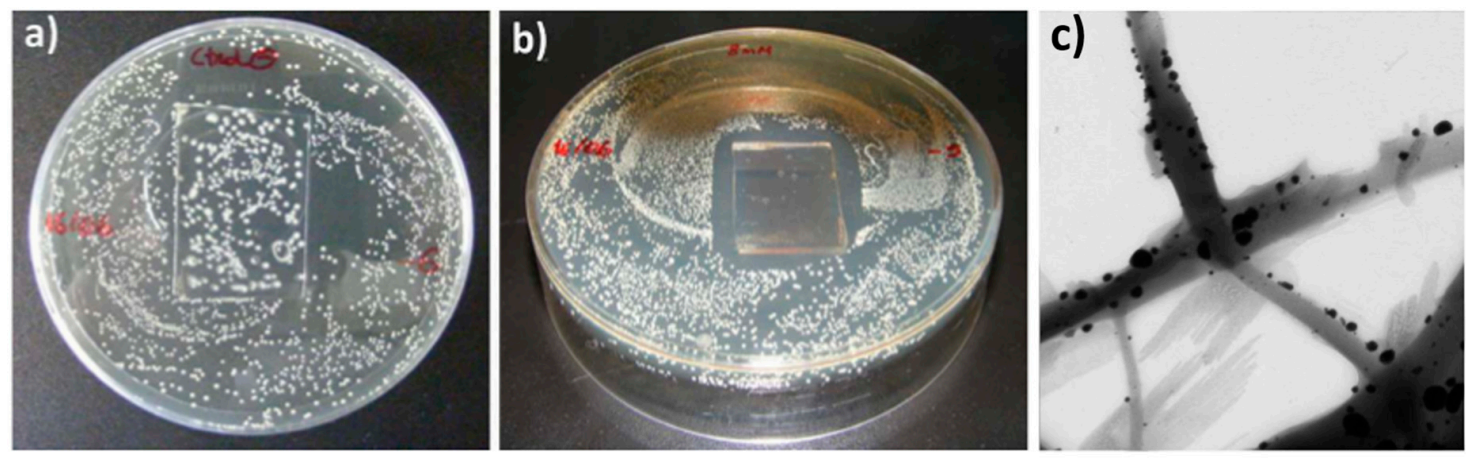

Figure 8. Bacteriological cultures of L. plantarum with two different samples: (a) reference sample with no silver nanoparticles and (b) silver loaded electrospun fiber mat. (c) TEM image of the AgNPs loaded electrospun fiber mat where it can be appreciated the AgNPs onto the electrospun nanofibers surface. Reproduced from [82] with permission; Copyright Elsevier 2012. 
Another approach based on the reduction of silver ions to silver nanoparticles is presented by Falleta et al. [83] as a function of two different mechanisms such as the UV-radiation exposure and a synthetic chemical reduction process. In this work, the preparation of silver-polyacrylate clusters has been obtained and the resultant coloration depends on molecular weight of the protective agent as well as the mechanism of reduction to silver nanoparticles. In Figure 9, the strong inhibition effect of the polyester fabrics against different types of microorganisms can be clearly observed.
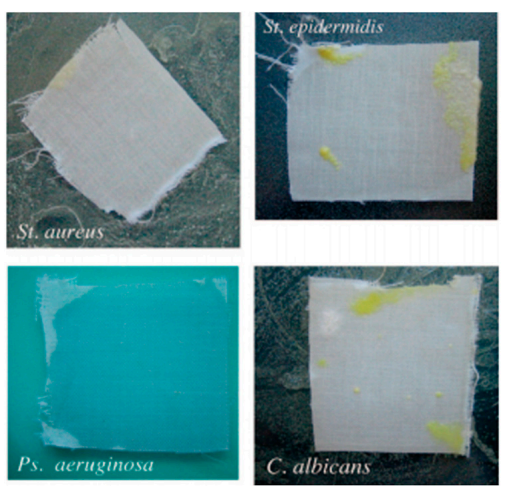

(a)
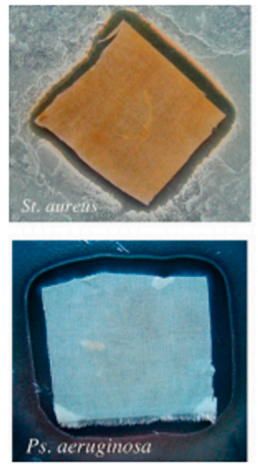
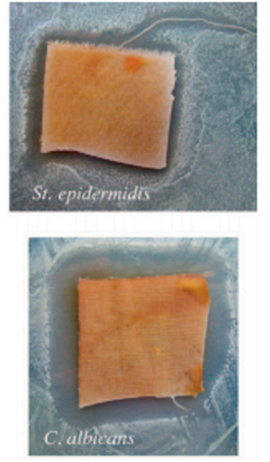

(b)

Figure 9. (a) Effect of untreated cotton samples and (b) effect of Ag-treated cotton samples toward the growth of the investigated stains. Reproduced from [83] with permission; Copyright American Chemical Society 2008.

According to this, silver nanoparticles (AgNPs) are an effective killing agent against a broad spectrum of Gram-positive and Gram-negative bacteria, the textile materials being one of the research fields which is experiencing a continuous growth because of possible applications in the medical sector leading to high performance products (atopic dermatitis, wound bandages, sterilization materials) or the manufacturing of high-added value textile. In this sense, multiple works focusing on the development of silver nanocomposites into textile fabrics can be found in the bibliography by using the sol-gel technology. Interesting results have been presented by Timin and Rumyantsev [84] where a silver-silica nanocomposite is fabricated by the hydrolysis and condensation of TEOS in the presence of diamminesilver (I) cation, indicating that the morphology and resultant size of the silver nanocomposites strongly depends on the amount of nanosilver in the silica matrix. The experimental results show an excellent antimicrobial activity against $E$. coli and S. aureous bacteria. Other relevant work also based on the sol-gel technology is presented by Mahltig et al. [85] where the antimicrobial efficiency as a function of the curing temperature is evaluated. In this work, textiles coated with inorganic silica layers containing silver nanoparticles have been fabricated by using the sol-gel method, inhibiting the growth of fungi and bacteria on the coated textiles. In other novel work, Mahltig and Textor [86] evaluated the combination of a high antimicrobial effect with a high durability after washing cycles, being these two factors of vital relevance for a further industrial production process. In another work, two different types of nanoparticles such as $\mathrm{AgNPs}$ and $\mathrm{TiO}_{2} \mathrm{NPs}$ are combined in order to fabricate multifunctional textile nanocomposite materials with desirable UV protective, antimicrobial effect and photocatalytic properties [87]. In fact, the inherent properties related to the $\mathrm{TiO}_{2} \mathrm{NPs}$ such as extraordinary photocatalytic activity, non-toxicity, high availability or biocompatibility, make them very useful for the manufacturing of high-value products. Accordingly, an interesting work that concerns the major effects that $\mathrm{TiO}_{2} \mathrm{NPs}$ can impart on textile materials (antibacterial activity, UV protection, self-cleaning properties) is evaluated by Radetic [88]. In this sense, related to the use of $\mathrm{TiO}_{2}$ NPs, another interesting work is presented by Khurana and Adiverakar [89] where high purity and crystalline nano titanium dioxide particles have been synthesized by using the sol-gel method. In this work, these $\mathrm{TiO}_{2} \mathrm{NPs}$ have been applied onto cotton fabrics with the aim of obtaining antimicrobial activity and the use of a binder has improved the resultant durability after successive washes. 
Once the antibacterial activity of $\mathrm{TiO}_{2} \mathrm{NPs}$ has been demonstrated, it is important to mention that other different metal oxide nanoparticles also show antimicrobial activity against Gram-positive and Gram-negative bacteria. A comparative study about the use of three specific metal oxide nanoparticles ( $\mathrm{ZnO}, \mathrm{CuO}$ and $\mathrm{Fe}_{2} \mathrm{O}_{3}$, respectively) which have been synthesized by sol-gel combustion is presented by Azam et al. [90]. In this work, the antibacterial activity against both Gram-negative (E. coli and P. aeruginosa) and Gram-positive (S. aureus and B. subtilis) have been evaluated. The experimental results indicate that $\mathrm{ZnO}$ nanoparticles have an excellent bactericidal potential, showing better results of antibacterial activity in comparison with the other two metal oxide nanoparticles. Farouk et al. [91] present a novel work based on the use of nanosized $\mathrm{ZnO}$ particles as an antibacterial finish for textiles. The $\mathrm{ZnO}$ nanoparticles embedded in a hybrid polymer sol have been applied onto textile materials (cotton and cotton/polyester) in order to obtain antibacterial activity. The results indicate that the antibacterial activity of the textiles is increased when the resultant particle size is reduced. This enhanced bioactivity related to the smaller particles is associated with the higher surface area to volume ratio. Finally, another important aspect related to the sol-gel technology is the high versatility to accept a wide variety of biocide compounds which are perfectly embedded in the silica matrix. In another work, Mahltig et al. [92] have reported the preparation of modified silica coatings which contain embedded biocide materials. More specifically, an exhaustive study about silica layers embedded silver, silver salts and biocidal ammonium quaternary salts is presented as a function of three specific parameters such as antimicrobial efficacy, wash-out and long-term behavior.

Other interesting works based on the use of other different wet-chemistry methods such as the layer-by-layer (LbL) technique for the design of novel antibacterial coatings can be also found in the bibliography. Urrutia et al. [93] fabricated nanotexturized coatings which have been tested in bacterial cultures of genus Lactobacillus, showing a good antimicrobial behavior against this type of bacteria. Based on the same hypothesis of nanotexturized coating by using the LbL is presented by the same author (Urrutia et al.) [94]. In this work, in situ synthesis of Ag NPs into LbL films is obtained by the sequential deposition of poly(allylamine hydrochloride) (PAH) and $\mathrm{SiO}_{2} \mathrm{NPs}$. In this approach, the amino groups of the PAH acted as an efficient reducing agent and as result, AgNPs have been successfully synthesized into the LbL films. All LbL coatings have been tested with gram-positive and gram-negative bacterial cultures of E. coli, S. aureus, and L. delbrueckii, respectively, showing an excellent antimicrobial behavior against these types of bacteria (more than $99.9 \%$ of killing efficiency in all cases of study).

A summary of the different antibacterial agents which are incorporated by the different methodologies as well as their corresponding antibacterial activities against a specific type of bacteria or fungi is summarized in Table 3.

Implant-related infections are one of the main causes of failure in orthopedics and trauma. These infections increase the associated costs by over $300 \%$ and reduce the quality of life of the patients and their physical functions [95]. The colonization of the implant by bacteria occurs in two phases: in a first reversible phase, the bacteria adhere to the implant surface; in the second phase, they collect together and produce a polymeric extracellular matrix, known as biofilm, which protects them from the immune system and systemic antibiotics, leading to an irreversible bacteria colonization of the implant. This biofilm formation, which is probably the most critical pathogenic event in the development of implant-related infections, is normally completed within 12-18 h [96-98].

Surface coating is the most widely used method to obtain antibacterial and anti-biofilm formation properties on a surface. Antibacterial coating technologies have been recently classified by Romanò et al. [99] in three main groups: pre-operative antibacterial local carriers or coatings, active surface modification and passive surface modification. The passive surface modification group includes all surfaces chemically or physically modified to prevent or reduce bacterial adhesion without releasing antibacterial agents. These methods are normally based on changing the surface energy and roughness of the material by chemical or physical methods, including hydrophilic or superhydrophobic surfaces, antiadhesive polymers, hydrogels and biosurfactants. Although the surface chemistry is 
essential to preventing the adhesion of bacteria and biofilm formation, it was observed that several organisms without any chemical protection are able to maintain their surface free of bacteria and biofilm formation. These organisms show different topographical features in the micro- and nano-scale providing them antibacterial properties: e.g., shark skin, pilot whale skin, lotus leaf and some insects' wing surfaces. Topographical modification of the resultant surfaces with nano- and microstructures has emerged as a potential tool for the fabrication of functionalized surfaces with antibacterial properties [100]. Some of the technologies usually applied for fabrication of antibacterial surfaces via surface micro- and nanostructuring are chemical etching (Black Silicon), physical vapor deposition (PVD), plasma irradiation, hydrothermal treatments, photolithography, electron-beam lithography and ablation by ultrashort pulsed lasers [101-107]. In Table 4, the advantages and disadvantages of these micro and nano-patterning technologies are shown.

According to the information provided in Table 4, one of the major limitations of these manufacturing technologies presented is the lack of scalability of the solution. Only in the case of using the direct laser structuring via ultrashort pulsed lasers, the covered area reaches the scale of meters. For this reason, the purpose of the research reported in this paper is to evaluate the effect of different surface topographies obtained via picosecond pulsed laser ablation technology on the proliferation of two different types of bacteria on titanium substrates.

A combination of micro- and nano-texturing (known as hierarchical structures) was designed and manufactured in order to avoid or reduce this proliferation without the incorporation of antimicrobial agents. As can be observed in Figure 10, the hierarchical structures generated by the laser in the titanium plates consist of pyramidal features at the microscale covered by nanoripples (laser-induced periodic surface structure: LIPSS). This hierarchical topography has been designed and manufactured to obtain different surface properties of the Titanium Grade 23 substrate, such as superhydrophobicity, which is one of the factors playing an important role on antimicrobial behavior.

Table 3. Summary of the antibacterial agents as well as deposition method evaluated in this work against a specific type of genus.

\begin{tabular}{|c|c|c|}
\hline Antibacterial Agent & Antibacterial Test & Deposition Method \\
\hline $\begin{array}{l}\text { Silver nanoparticles (in situ synthesis by a } \\
\text { chemical reduction method) }\end{array}$ & Lactobacillus plantarum & Electrospinning [82] \\
\hline $\begin{array}{l}\text { Silver nanoparticles (in situ synthesis by a } \\
\text { chemical reduction method) }\end{array}$ & Lactobacillus plantarum & Sol-gel dip-coating process [26] \\
\hline Silver-poly(acrylate) clusters & $\begin{array}{l}\text { Staphylococcus aureus, Staphylococcus epidermidis, } \\
\text { Pseudomonas aeruginosa, Candida albicans }\end{array}$ & $\begin{array}{l}\text { Immersion in the polyacrylate } \\
\text { dispersions [83] }\end{array}$ \\
\hline Diamminesilver (I) silver $\left[\mathrm{Ag}\left(\mathrm{NH}_{3}\right)_{2}\right]^{+}$ & Staphylococcus aureus and Escherichia coli & Sol-gel dip-coating process [84] \\
\hline $\begin{array}{c}\text { Silver nanoparticles (study as a function of } \\
\text { the intensity and variation of the } \\
\text { curing treatment) }\end{array}$ & $\begin{array}{c}\text { Fungi (Aspergillus niger) and bacteria (Bacillus } \\
\text { subtilis and Pseudomonas putili) }\end{array}$ & Sol-gel dip-coating process [85] \\
\hline Silver containing silica sols & Escherichia coli & $\begin{array}{l}\text { Pad-dry cure process; high long } \\
\text { term-stability after washing cycles [86] }\end{array}$ \\
\hline Silver and titanium oxide nanoparticles & $\begin{array}{c}\text { Gram-negative bacteria (Escherichia coli); } \\
\text { Gram-positive bacteria (Staphylococcus aureus); } \\
\text { Fungi (Candida albicans) }\end{array}$ & $\begin{array}{c}\text { Dip-coating process, } \\
\text { Multifunctionality (UV protection and } \\
\text { photocatalytic properties) [87] }\end{array}$ \\
\hline Titanium oxide nanoparticles & Staphylococcus aureus and Escherichia coli & $\begin{array}{l}\text { Sol-gel method [89]; Use of a binder to } \\
\text { improve the durability after } \\
\text { washing cycles }\end{array}$ \\
\hline $\begin{array}{l}\text { Metal oxide nanoparticles }(\mathrm{ZnO}, \\
\left.\qquad \mathrm{CuO} \text { and } \mathrm{Fe}_{2} \mathrm{O}_{3}\right)\end{array}$ & $\begin{array}{l}\text { Gram-negative bacteria (Escherichia Coli and } \\
\text { Pseudonomas aueginosa); Gram-positive bacteria } \\
\text { (Staphylococcus aureus and Bacillus subtilis) }\end{array}$ & Sol-gel combustion method [90] \\
\hline Metal oxide nanoparticles $(\mathrm{ZnO})$ & $\begin{array}{l}\text { Gram-negative bacterium (Escherichia coli); } \\
\text { Gram-positive bacterium (Micrococus luteus) }\end{array}$ & $\begin{array}{l}\text { Inorganic/organic hybrid coating } \\
\text { polymer [91] }\end{array}$ \\
\hline $\begin{array}{c}\text { Silica coating embedding biocides (silver, } \\
\text { silver salts and ammonium } \\
\text { quaternarium salts) }\end{array}$ & $\begin{array}{l}\text { Inhibition of bacteria (E. coli) and fungi } \\
\text { (Aspergillus niger) }\end{array}$ & Long-term stability [92] \\
\hline $\begin{array}{l}\text { Silica nanoparticles combined with a high } \\
\text { surface area }\end{array}$ & Lactobacillus plantarum & Layer-by-layer assembly [93] \\
\hline In situ synthesis of silver nanoparticles & $\begin{array}{l}\text { Escherichia coli, Staphylococcus aureus and } \\
\text { Lactobacillus plantarum }\end{array}$ & Layer-by-layer technique [94] \\
\hline
\end{tabular}


Table 4. Micro- and nano-patterning technologies used for manufacturing antibacterial surfaces: Advantages and Disadvantages.

\begin{tabular}{|c|c|c|c|c|}
\hline Structuring Technique & Advantages & Disadvantages & Antibacterial Capacity & Scalability \\
\hline Chemical Etching (Black Silicon) [101] & $\begin{array}{l}\text { Biomimetic (nano-features similar } \\
\text { to those observed in nature) }\end{array}$ & $\begin{array}{l}\text { Material limitation (silicon); } \\
\text { Time consuming ( } 5 \mathrm{~min}-100 \mathrm{~mm}^{2} \text { Surface area); } \\
\text { Lack of control on pattern dimensions }\end{array}$ & $\begin{array}{l}\text { P. aeruginasa: } 4.3 \times 10^{5} ; \text { S. aureus: } \\
4.5 \times 10^{5} ; \text { B. subtilis: } 1.4 \times 10^{5}\end{array}$ & (2) \\
\hline $\begin{array}{l}\text { Hydrothermal treatments (Titanium } \\
\text { nanowires) [102] }\end{array}$ & Size control (biomimetic) & $\begin{array}{l}\text { Material limitation (Titanium); } \\
\text { Time consuming }\left(1 \mathrm{~mm} \text { growth requires } 1 \mathrm{~h} \text { at } 240{ }^{\circ} \mathrm{C}\right) \text {; } \\
\text { Expensive process }\end{array}$ & $\begin{array}{l}\text { S. aureus, E. faecali, } K \text {. } \\
\text { pneumoniae: }<10 \% \text { (stain-dead } \\
\text { cells); P. aeruginosa, E. coli, B. } \\
\text { subtilis: } 40 \%<\varepsilon<80 \% \\
\text { (stain-dead cells) }\end{array}$ & (2) \\
\hline $\begin{array}{l}\text { Pulsed Plasma Polymerization + UV } \\
\text { irradiation(photolitography) [103] }\end{array}$ & $\begin{array}{l}\text { Substrate independent method } \\
\text { (polymeric coating); } \\
\text { High resolution }\end{array}$ & $\begin{array}{l}\text { Geometrical restrictions (planar surfaces); } \\
\text { Photocurable polymeric materials are required; } \\
\text { Time consuming process }\end{array}$ & $\begin{array}{l}\text { E. coli: } 13 \%-33 \% \text { bacterial } \\
\text { adhesion reduction after } 14 \mathrm{~h}\end{array}$ & $\oplus$ \\
\hline $\begin{array}{l}\text { Direct laser interference } \\
\text { patterning(DLIP) [104] }\end{array}$ & $\begin{array}{l}\text { High quality nano-features in a } \\
\text { wide range of materials }\end{array}$ & $\begin{array}{l}\text { Limited to flat samples; } \\
\text { Patterned dimensions depends on the laser } \\
\text { characteristics (wavelength); } \\
\text { Maximum area covered by this technology: } 10-15 \mathrm{~cm} \\
\text { diameter (via Lloyd's mirror) }\end{array}$ & $\begin{array}{l}\text { S. aureus: up to } 60 \% \text { reduction } \\
\text { in adhesion }\end{array}$ & $\oplus$ \\
\hline Electron Beam Evaporator [105] & Size control & $\begin{array}{l}\text { Limited to a short range of materials (metals); } \\
\text { Vacuum chamber and electron gun required; } \\
\text { Expensive process. Small areas. }\end{array}$ & $\begin{array}{l}\text { Decreased adhesion on } S \text {. } \\
\text { aureus, epidermidis and } \\
\text { aeruginosa }(10 \%<\varepsilon<40 \% \text {, } \\
\text { depending on the bacteria) }\end{array}$ & (2) \\
\hline Ultrashort pulsed laser ablation [106] & $\begin{array}{l}\text { Hierarchical structures (micro and } \\
\text { nano); } \\
\text { Direct nanostructuring of a wide } \\
\text { variety of materials; } \\
\text { Possibility of large area structuring. }\end{array}$ & $\begin{array}{l}\text { Nanoripples emerged more likely when metallic } \\
\text { surfaces are considered; } \\
\text { Time consuming; } \\
\text { Expensive equipment (but robust and implemented in } \\
\text { industrial environments). }\end{array}$ & $\begin{array}{l}\text { On titanium. Decreased } \\
\text { adhesion on P. aeruginosa } \approx 90 \% \\
\text { No effects on S. aureus. }\end{array}$ & (:) \\
\hline Roll to roll Nanostructuring [107] & $\begin{array}{l}\text { Replication of large areas via } \\
\text { nanostructuring of the roll- }- \text { die }\end{array}$ & $\begin{array}{l}\text { Only suitable for nanostructuring flat polymeric films; } \\
\text { Manufacturing in two steps: Nanostructuring of the } \\
\text { roll and replication via roll to roll; } \\
\text { Time consuming }\end{array}$ & $\begin{array}{l}\text { E. coli: } 32 \% \text { reduction in } \\
\text { bacterial adhesion, considering } \\
\text { PS, PE and PC }\end{array}$ & (:) \\
\hline
\end{tabular}

: : Good; $:$ : Acceptable; $:$ : Poor. 


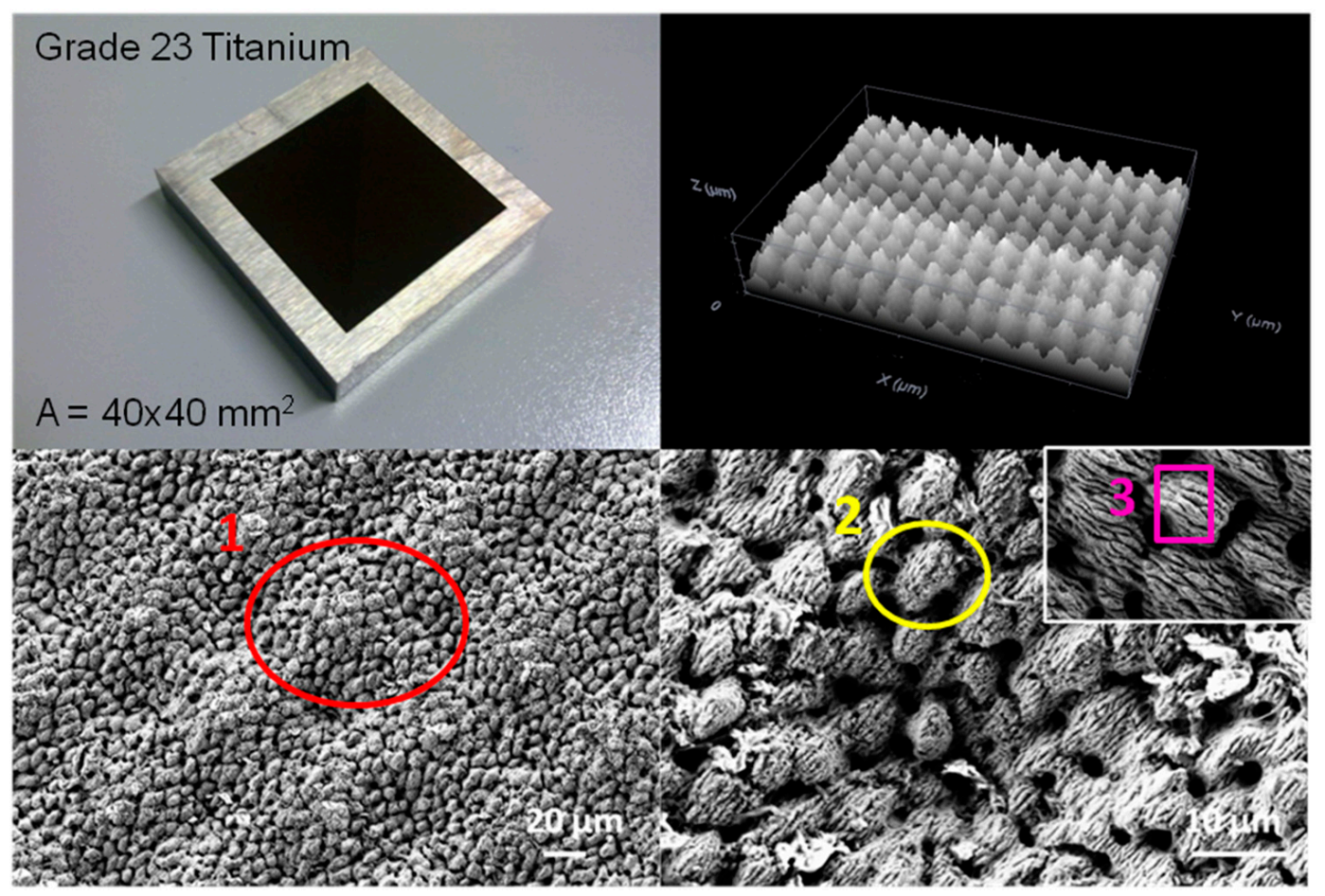

Figure 10. Hierarchical structures generated on Titanium Grade 23 by picosecond laser texturing: (1) Pyramidal structures; (2) Micro-humps; and (3) nanoripples.

The material composition before and after picosecond laser treatment is analyzed by EDS (Energy Dispersive Spectroscopy) in two different surfaces: out of the laser treated area (labelled as Spectrum 1) and in the laser textured surface (labelled as Spectrum 3), see Figure 11. It is worth noting that the semi-quantitative analysis of the material composition on both areas showed increments of $23 \%$ on the oxygen concentration in the area affected by the laser radiation. This result indicates that oxidation of the titanium alloy is promoted by the laser-texturing technique even when ultra-short pulses are considered.

We studied the antibacterial activity of the test surfaces against Staphylococcus aureus ATCC 6538P and Staphylococcus epidermidis ATCC 12228 using the standard JIS Z 2801:2010/A1:2012. According to the standard, an antibacterial product is determined to have antibacterial effectiveness when the antibacterial activity $(R)$ is 2.0 or more. In the case of $S$. aureus, the Value of the antimicrobial activity $(R)$ was 1.65 and a percent Reduction of $98 \%$. However, in the case of S. epidermidis, the value of the antimicrobial activity was 0.64 and a percent reduction of $77 \%$. According to these results, it is worth noting that the antimicrobial effectiveness of the topography obtained by laser texturing depends a lot on the bacterial type considered. Additionally, even though the topography selected showed an improvement of the antibacterial activity, leading to $R$ values higher than those observed in the state of the art for different passive surface modification techniques (Table 1), this value did not reach the antibacterial effectiveness threshold considered by the standard, which indicates that the laser-texturing technique is an excellent approach for improving the antibacterial activity but in order to reach the values established by the standard, a combination of this technique with active surface modification techniques (such as PVD coatings doped with antimicrobial agents) is required. 

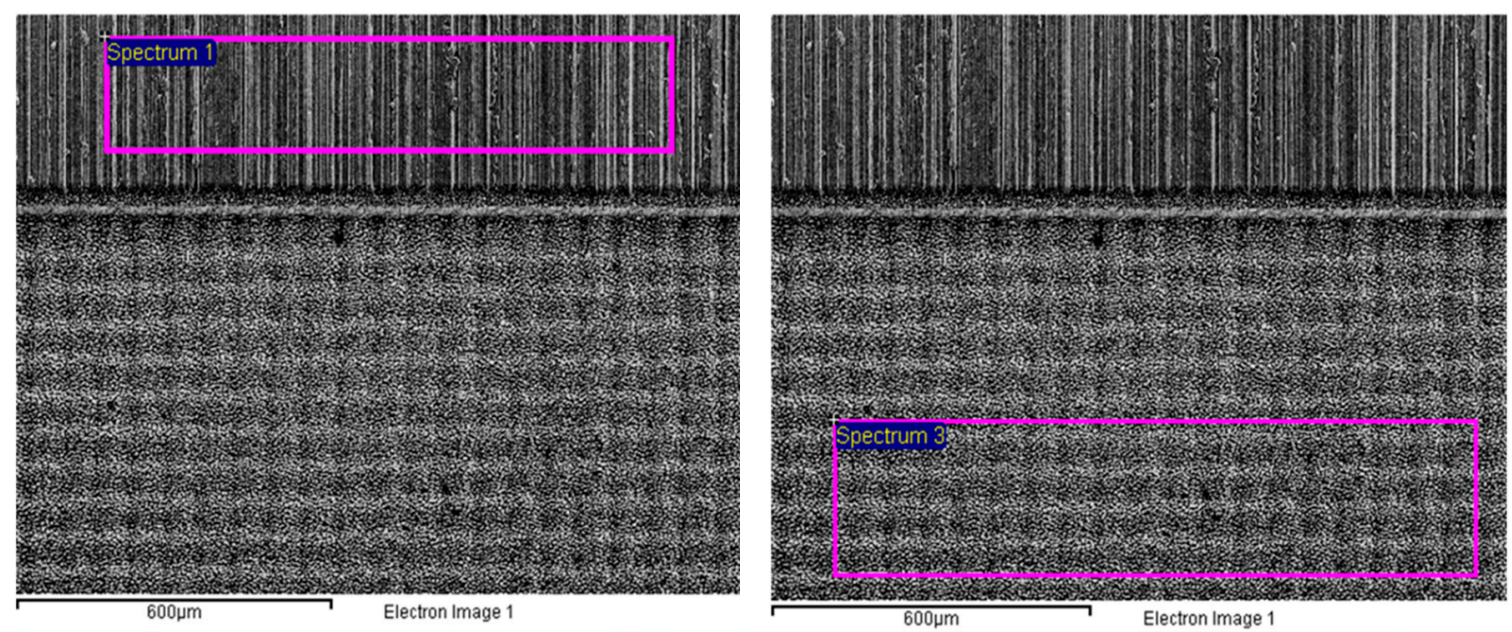

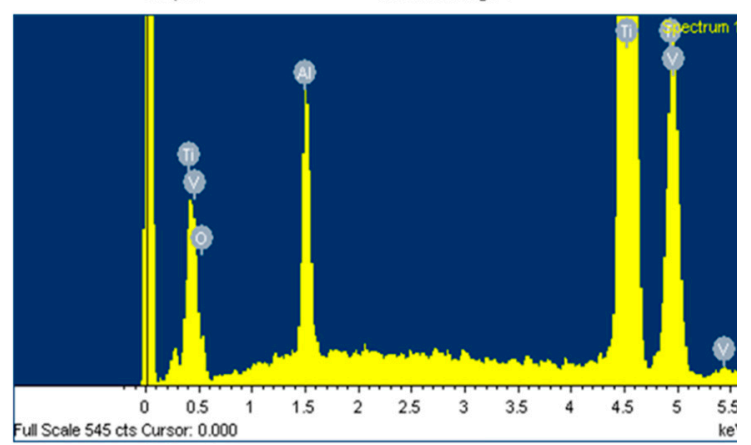

(a)

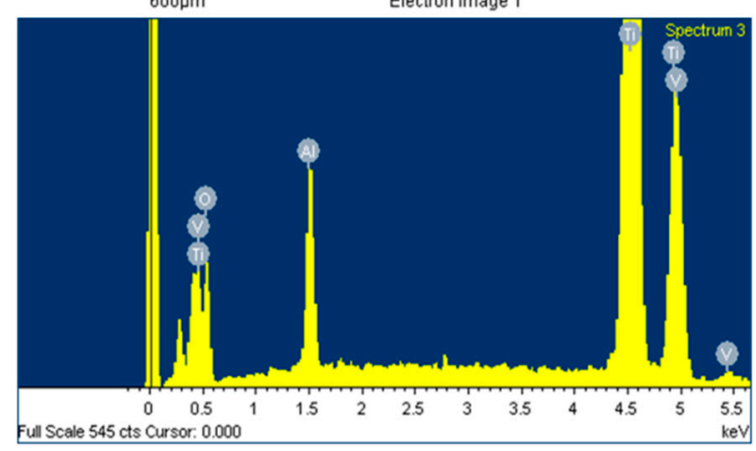

(b)

Figure 11. EDS analysis of the Titanium Grade 23 substrate considering (a) a surface without laser treatment (Spectrum 1, O: $0 \mathrm{wt} \%$ ) and (b) a surface where laser texturing process was performed (Spectrum 3, O: $23 \mathrm{wt} \%$ ).

\subsection{Optical Fiber Sensors}

Optical fiber technology has produced an authentic revolution in the telecommunications field in recent decades due to its intrinsic advantages (light-weight, portability, small size, and capability to perform "in vivo" or remote sensing measurements, immunity to electromagnetic interferences) which are a key factor for sensing applications [108,109]. Due to all these potential advantages, the scientific community is continuously developing novel market niches for its implementation in a wide variety of different areas such as environmental monitoring, biomedicine, food or chemical industry, gas sensing, clinical analysis or safety at work [110-113]. An important consideration is that the optical fiber field has shown a considerable growth thanks to the implementation and development of nanostructured thin films onto diverse optical fiber configurations. These nanostructured coatings make possible an enhancement in the response time as well as in the resultant sensitivity [114-121]. In addition, the presence of nanoparticles in these sensitive thin films has resulted in the design of high-performance fiber-optic sensors due to the inherent properties of the nanoparticles such as high surface area ratio and porosity [122-126]. Among them, the use of metallic nanoparticles for sensing applications is of great interest due to the presence of strong absorption bands in the visible region, known as Localized Surface Plasmon Resonances (LSPR) [127]. These optical resonances are due to the coupling of certain modes of the incident light to the collective oscillation of the conduction electrons of the metallic nanoparticles [128]. In this sense, one of the most relevant aspects of the synthesis of metallic nanoparticles, mostly silver (AgNPs) or gold nanoparticles (AuNPs), is that there is a high dependence between their optical properties (color formation) and the resultant morphology (shape and size). The possibility of monitoring the evolution of the LSPR wavelength position by UV-Vis measurements and the corresponding color formation makes possible the design of metallic 
nanoparticles with a specific shape and size [129]. An illustrative example can be observed in Figure 12 where a multicolor silver map (Figure 12a) is presented as a function of a strict control of both protective (polyacrylic acid sodium salt, PAA) and reducing (dimethylamino borane, DMAB) agents during the synthesis process by using a chemical reduction method for a fixed molar concentration of the loading agent (silver nitrate, $\mathrm{AgNO}_{3}$ ). Figure $12 \mathrm{~b}$ shows the evolution of the optical absorption bands related to the LSPR in two well-differentiated regions (region 1 from 400 to $500 \mathrm{~nm}$, region 2 from 600 to $700 \mathrm{~nm}$ ) at a fixed PAA molar concentration of $25 \mathrm{mM}$ when the reducing agent (DMAB) is gradually increased.
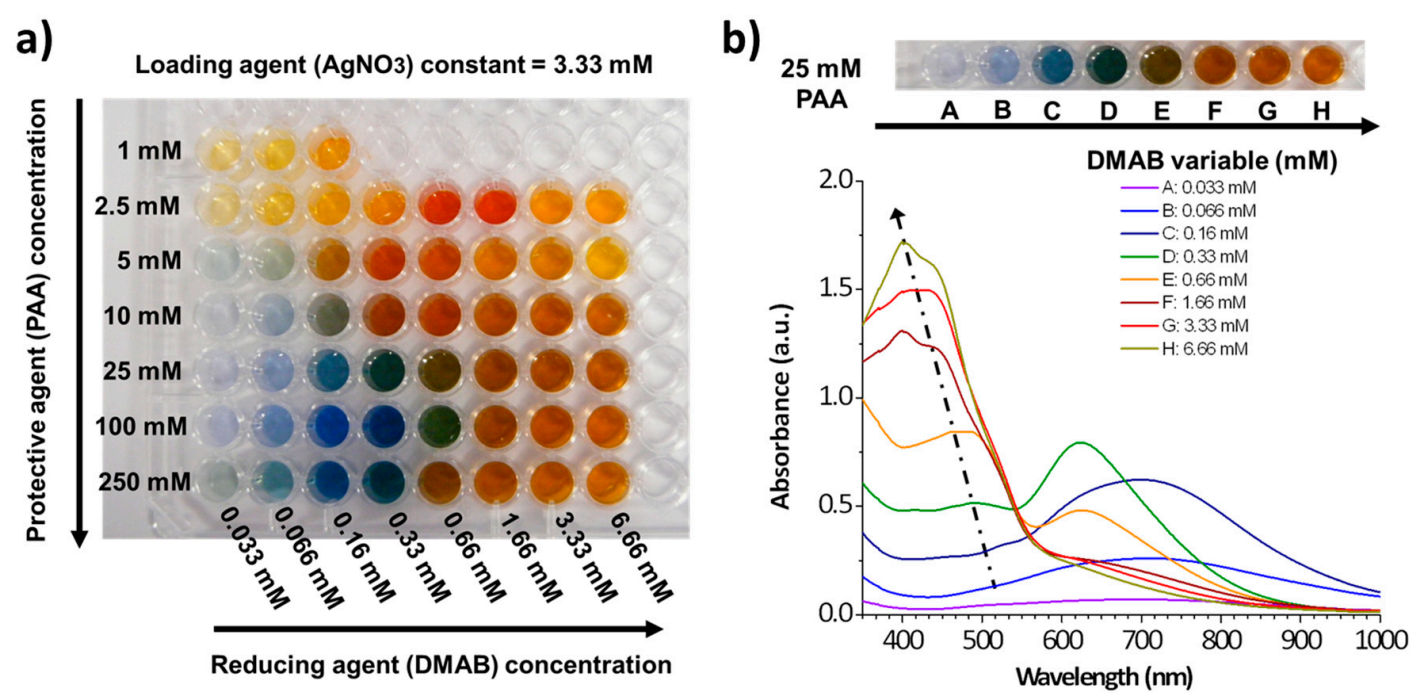

Figure 12. (a) Photograph of the multicolor silver map obtained as a function of variable protective agent (PAA from $1 \mathrm{mM}$ to $250 \mathrm{mM}$ ) and reducing agent (DMAB from 0.033 to $6.66 \mathrm{mM}$ ), respectively. (b) UV-Vis spectra of the silver solutions prepared with variable DMAB concentration at a constant PAA concentration of $25 \mathrm{mM}$ (fifth line of the multicolor silver map). Reproduced from [129] with permission; Copyright Springer 2013.

It is important to remark that this specific optical phenomenon (LSPR) is of great interest for sensing or biosensing applications because it can be affected by the surrounding refractive medium of the nanoparticles. As a result, the design of novel optical fiber sensors can be created with outstanding properties such as high sensitivity, selectivity, robustness or optical self-reference. In addition, depending on the location of the sensitive coating along the optical fiber, two different architectures such as reflection or transmission can be considered. In the case of the reflection scheme, the sensing material is deposited at the end of the tip fiber, it being the optical coupler which guides the signal from the light source to the sensor. However, in the case of the transmission scheme, there is a direct optical path between the light source and the receiver, respectively. Figure 13 shows a representative scheme about both types of sensing configurations as a function of the location of the sensitive coating [130].

Due to these attractive properties related to the LSPR phenomenon of metallic nanoparticles combined with the intrinsic advantages of optical fiber and the different possibilities related to the architecture of the sensitive coating, the field of optical fiber sensors has extended their applicability to measure biological, chemical, environmental, medical or physical parameters, among others [131-134]. Most of the papers found in the literature are focused on the incorporation of gold nanoparticles (AuNPs) into thin films because this type of nanoparticle presents additional advantages such a great biocompatibility, non-reactivity, good chemical stability and easiness for a further functionalization $[135,136]$. The possibility of the implementation of self-assembled multilayers with metallic nanoparticles adsorbed onto optical fibers provides a simple, fast, robust and low-cost platform for LSPR biosensing applications. In this sense, representative examples of the incorporation of metallic gold nanoparticles inside different types of nanocoatings can be found in the literature [137-140] for the design of LSPR fiber probes for biosensing applications. 
For example, Figure 14 shows one of the techniques previously commented upon. Sol-gel technology is used for the immobilization and location of the AuNPs according to a specific reaction mechanism (Figure 14a), whereas the reflection LSPR fiber-optic probe is described in Figure $14 \mathrm{~b}$ for the quantitative determination of hydrofluoric acid solution [137].

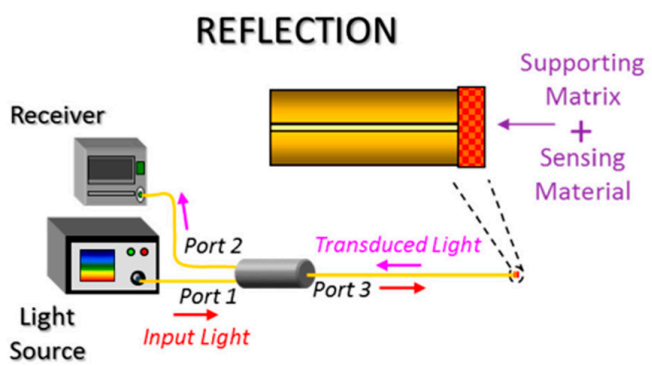

(a)

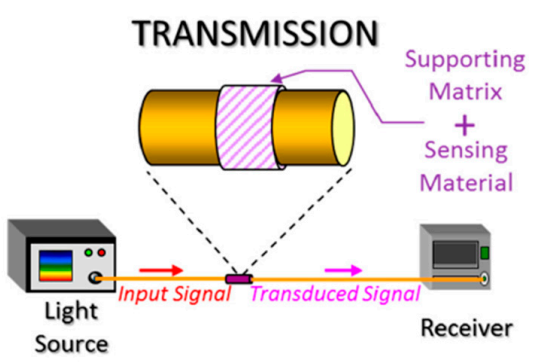

(b)

Figure 13. Schematic representation of the different architectures used for optical fiber sensors such as (a) reflection mode and (b) transmission mode. Reproduced from [130] with permission from Elosua et al. (2017).

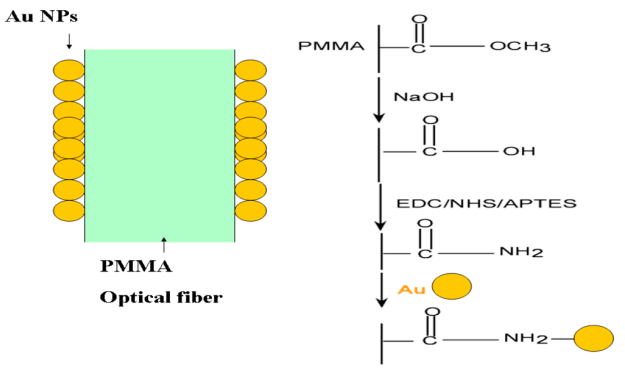

(a)

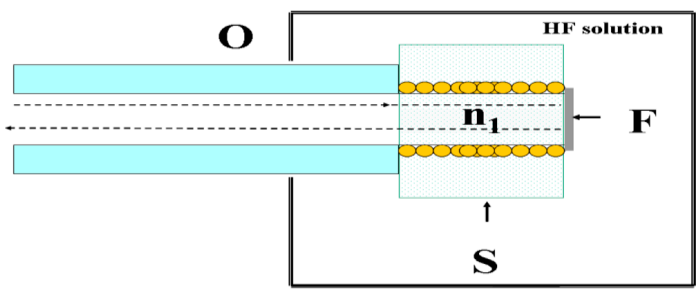

$\mathrm{S}: \mathrm{SiO}_{2}$ bulk from Sol-gel coating F: with a silver surface

(b)

Figure 14. (a) The diagram of gold nanoparticles immobilized on PMMA optical fiber by using a sol-gel coating. (b) Schematic diagram of the reflection-based LSPR fiber-optic probe. Reproduced from [137] with permission from Chen et al. (2011).

Another interesting example based on a reflection mode is presented by Jia et al. [138]. In this work, gold nanospheres have been successfully coated onto the tip of an optical fiber with the aim of designing a Localized Surface Plasmon Resonance DNA biosensor. In a first step, the nanoparticle size ( $20 \mathrm{~nm}$ and $80 \mathrm{~nm}$, respectively) has been evaluated in order to fabricate a DNA biosensor with a higher sensitivity. The experimental data showed that gold nanoparticles with a size of $80 \mathrm{~nm}$ had a higher refractive index sensitivity $(218.98 \mathrm{~nm} / \mathrm{RIU})$ than gold nanoparticles with a size of $20 \mathrm{~nm}(82.86 \mathrm{~nm} / \mathrm{RIU})$, respectively. In addition, in a second step, a wavelength interrogation mode has been used to determine the sensitivity of the sensor and the results showed a red shift of the LSPR absorption band when the concentration is increased (from 0 to $500 \mathrm{nmol} / \mathrm{L}$, respectively). In addition, the results indicated that the optical fiber sensor showed several advantages such as a small sample consumption, easy fabrication and high sensitivity, being possible to detect a low target DNA ( $50 \mathrm{nmol} / \mathrm{L})$. Finally, Figure 15 represents a schematic diagram of the detection system as well as the aspect of the optical fiber with the gold nanospheres coated onto the tip with its corresponding sensitivity to target DNA concentration. 


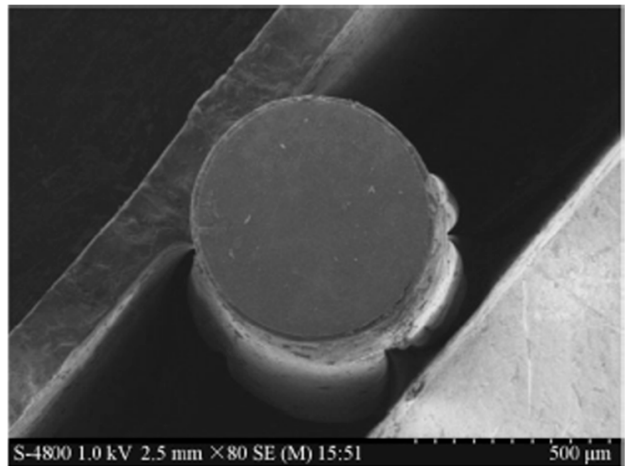

(a)

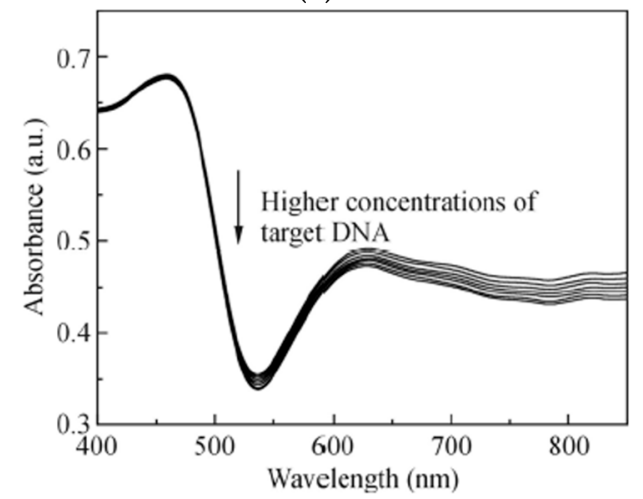

(c)

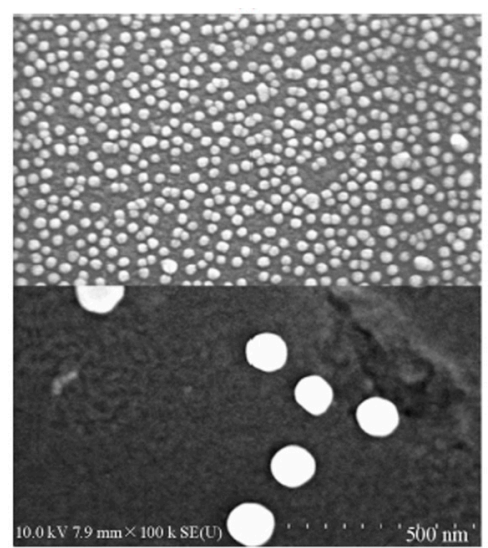

(b)

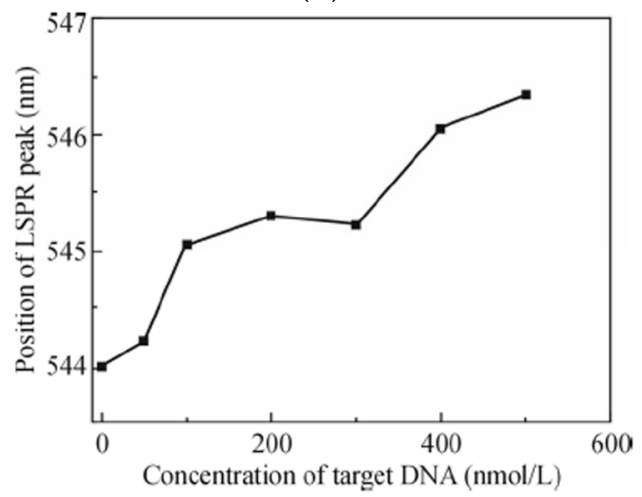

(d)

Figure 15. SEM images of the tip of (a) the fiber sensor and (b) the electrostatic self-assembly of monolayers of gold nanoparticles (AuNPs) of different sizes; (c) The absorbance spectra of the gold nanoparticles coated sensor for DNA concentration ranging from 0 to $500 \mathrm{nmol} / \mathrm{L}$ and (d) relationship between position of the LSPR peak and target DNA concentration. Reproduced from [138] with permission; Copyright Springer 2016.

Another approach based on an nm-thickness composite gold thin film of AuNPs and polyelectrolytes is presented by Wan et al. [139] for biosensing applications. In this work, layer-by-layer assembly has been used to perform a nanocoating onto the end-face of the optical fiber in order to fabricate a Localized Surface Plasmon Resonance fiber probe for the detection of the biotin-streptavidin bioconjugate pair. The results indicate that there is a red-shift to shorter wavelengths related to the LSPR peak when the concentration of the streptavidin solution is increased, as can be observed in Figure 16.

(a)

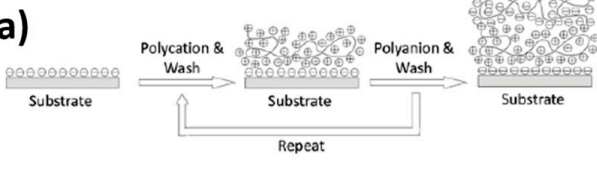

whitelight source

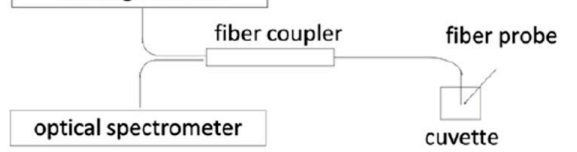

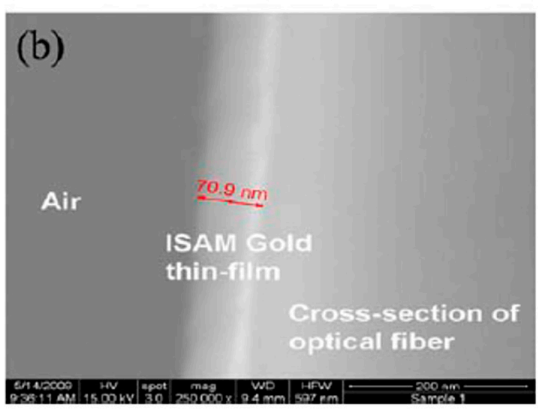

Figure 16. Cont. 
c)

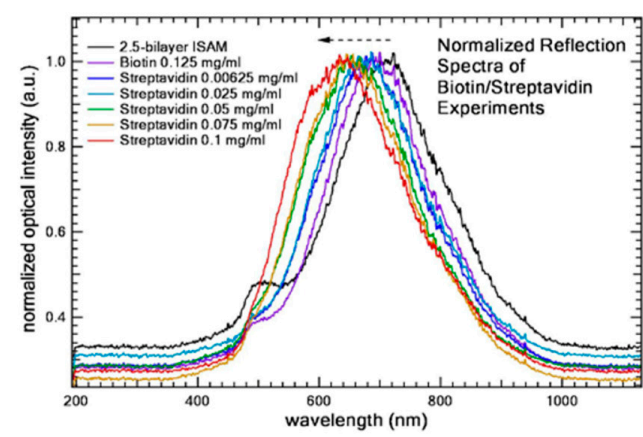

d)

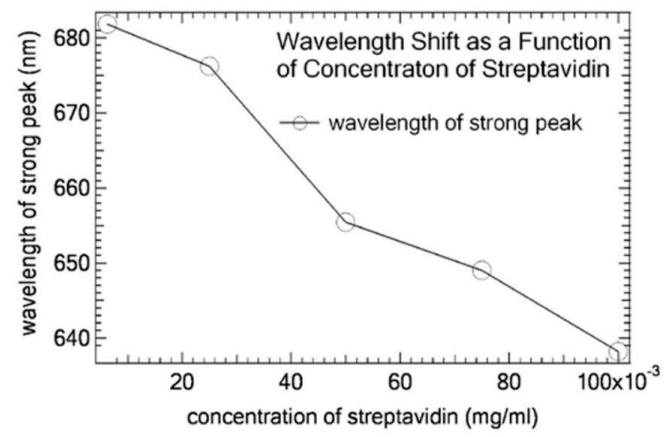

Figure 16. (a) Schematic representation of the optical setup and the fabrication of the thin film onto the end-face of the fiber; (b) SEM picture of the cross-section of a cleaved optical fiber coated by 10-bilayers; (c) normalized reflection spectra measured in air as a function of the concentration of streptavidin; (d) wavelength shift of the LSPR peak as a function of streptavidin concentration. Reproduced from [139] with permission from Wan et al. (2010).

Another work based on the assembly of AuNPs in a polyelectrolyte multilayer structure is presented by Shao et al. (2010) [140]. In this work, transmission architecture has been used for the design of an optical fiber LSPR biosensor (see Figure 17). In Figure 17a, can be clearly observed that the gold nanoparticle assembled film (sensing layer), which is built onto a trilayer polyelectrolyte structure, modified the sidewall of an unclad optical fiber. In addition, two well-dispersed AuNPs (spherical in morphology) with a single plasmon band have been used for the preparation of the LSPR sensing films. The resultant optical fiber sensor has been used to detect the changes of the bulk phase refractive index and the assays of antibodies. More specifically, the optical fiber LSPR sensor has been modified by rabbit IgG in order to detect goat anti-rabbit IgG, as can be observed in Figure 17b. The experimental results indicate that after pumping different concentrations of goat anti-rabbit IgG, the resultant peak intensity is gradually elevated when the goat anti-rabbit IgG concentration is increased. These results related to this optical fiber biosensor present several additional advantages such as a very good reproduction, a rapid preparation and a high sensitivity, it being a promising alternative as a portable immune-sensor.

One of the main advantages of the layer-by-layer assembly is the high versatility to entrap different types of metallic nanoparticles (silver, gold, copper) as well as a great capability for incorporating nanoparticles with a wide variety of shapes (spherical, hexagonal, triangle, rod) and sizes (micrometric or nanometric range) into the thin-films [141-143]. In order to corroborate the morphological aspect of the LbL coatings based on an adequate incorporation of metallic nanoparticles with different shapes, AFM images have been used to determine the distribution in the outer surface of the coatings, as it can be appreciated in Figure 18.

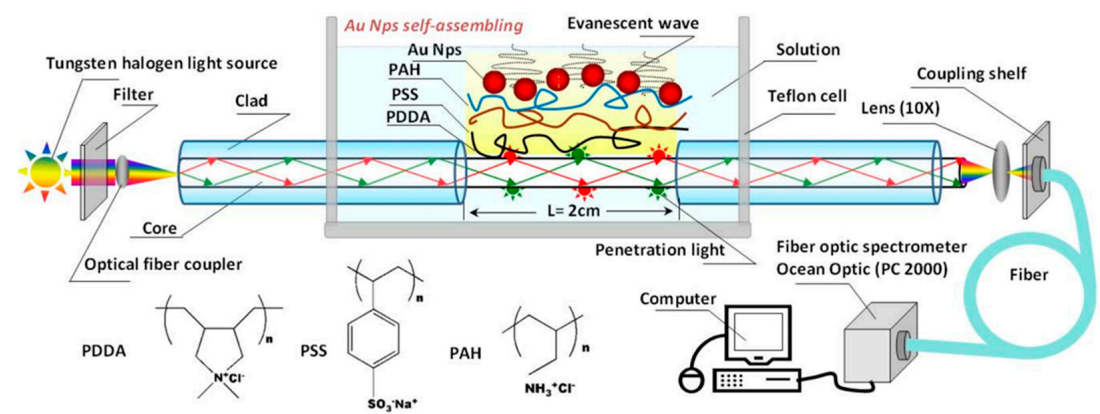

(a)

Figure 17. Cont. 


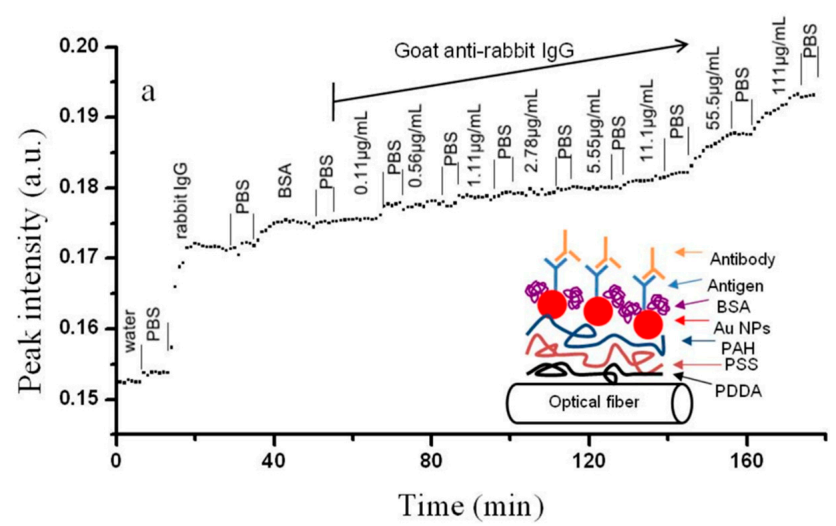

(b)

Figure 17. (a) Schematic representation of the experimental setup of the LSPR optical fiber sensor by using a trilayer polyelectrolyte structure which has been used to assemble the gold nanoparticles; (b) LSPR biosensing at different concentrations of goat anti-rabbit IgG from 0.11 to $100 \mu \mathrm{g} / \mathrm{mL}$. Reproduced from [140] with permission from Shao et al. (2010).

a)

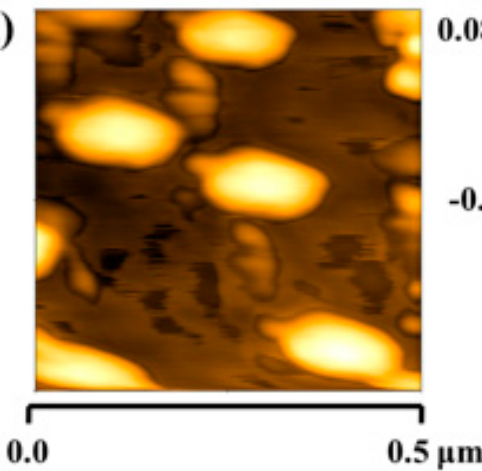

$0.086 \mu \mathrm{m} \quad$ b)

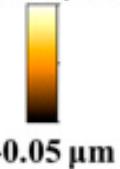

c)

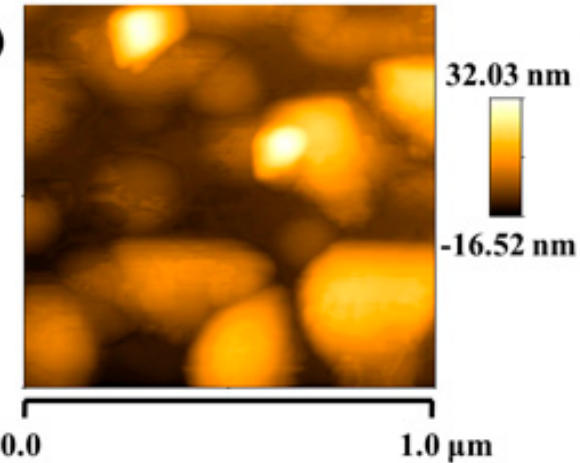

b)

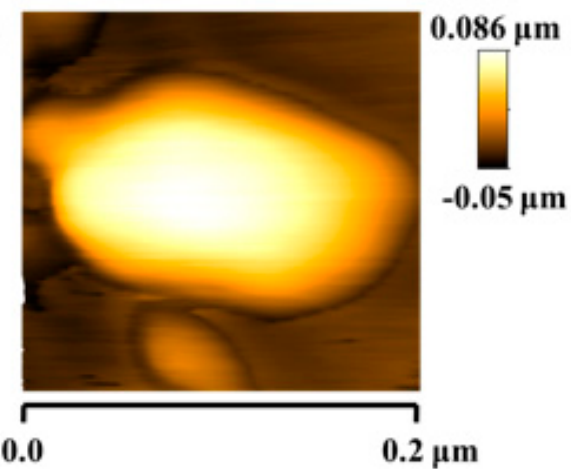

d)

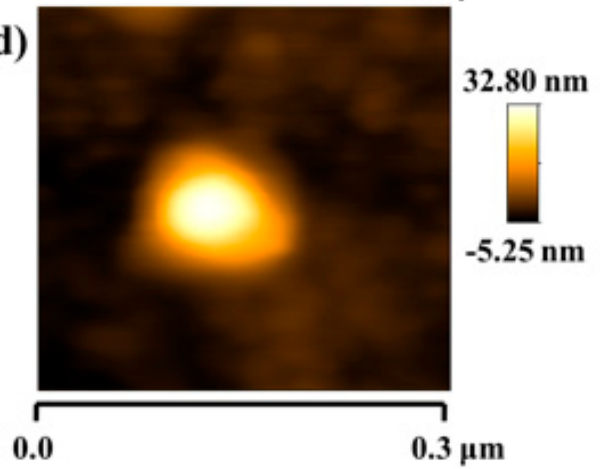

Figure 18. (a,b) AFM images in tapping mode for the LbL-E coatings in order to corroborate the presence of nanorods of an approximated size of $200 \mathrm{~nm}$; (c,d) AFM images in tapping mode for the LbL-E coatings in order to corroborate the presence of both spherical nanoparticles and particles of higher size (clusters).

Once these metallic nanoparticles with a specific shape have been successfully incorporated into the LbL thin films, Rivero et al. have developed novel optical fiber sensors based on the implementation of these sensitive coatings for the detection of physical, chemical or biological parameters such as Relative Humidity ( $\mathrm{RH})$, refractive index (RI), $\mathrm{pH}$ changes or human breathing [144-149]. It is important to remark that it is the first research group in reporting optical fiber sensors based on the simultaneous apparition of two different optical phenomena such as the Localized Surface Plasmon Resonance (LSPR) and lossy-mode Resonance (LMR) for sensing applications [144]. Previous works have reported the fabrication of LMR devices for sensing applications because the LMR band can 
be generated by using a broad range of supporting materials (polymer, semiconductor), making possible the apparition of multiple absorption bands in the visible or infrared region [150]. However, practical applications for sensing devices based on the simultaneous combination of both LSPR and LMR phenomena are of great interest in the field of optical fiber because it yields the design of self-referenced optical sensors. More specifically, the LSPR band is used as a reference signal, whereas the LMR bands are used as a sensing signal due to the great difference in their sensitivities to the parameter of study. Figure 19 presents a clear example for the fabrication of dual LSPR-LMR optical fiber devices based on the incorporation of metallic nanoparticles into layer-by-layer films, it being possible to observe their corresponding sensitivities to Relative Humidity, human breathing, $\mathrm{pH}$ or refractive index values.
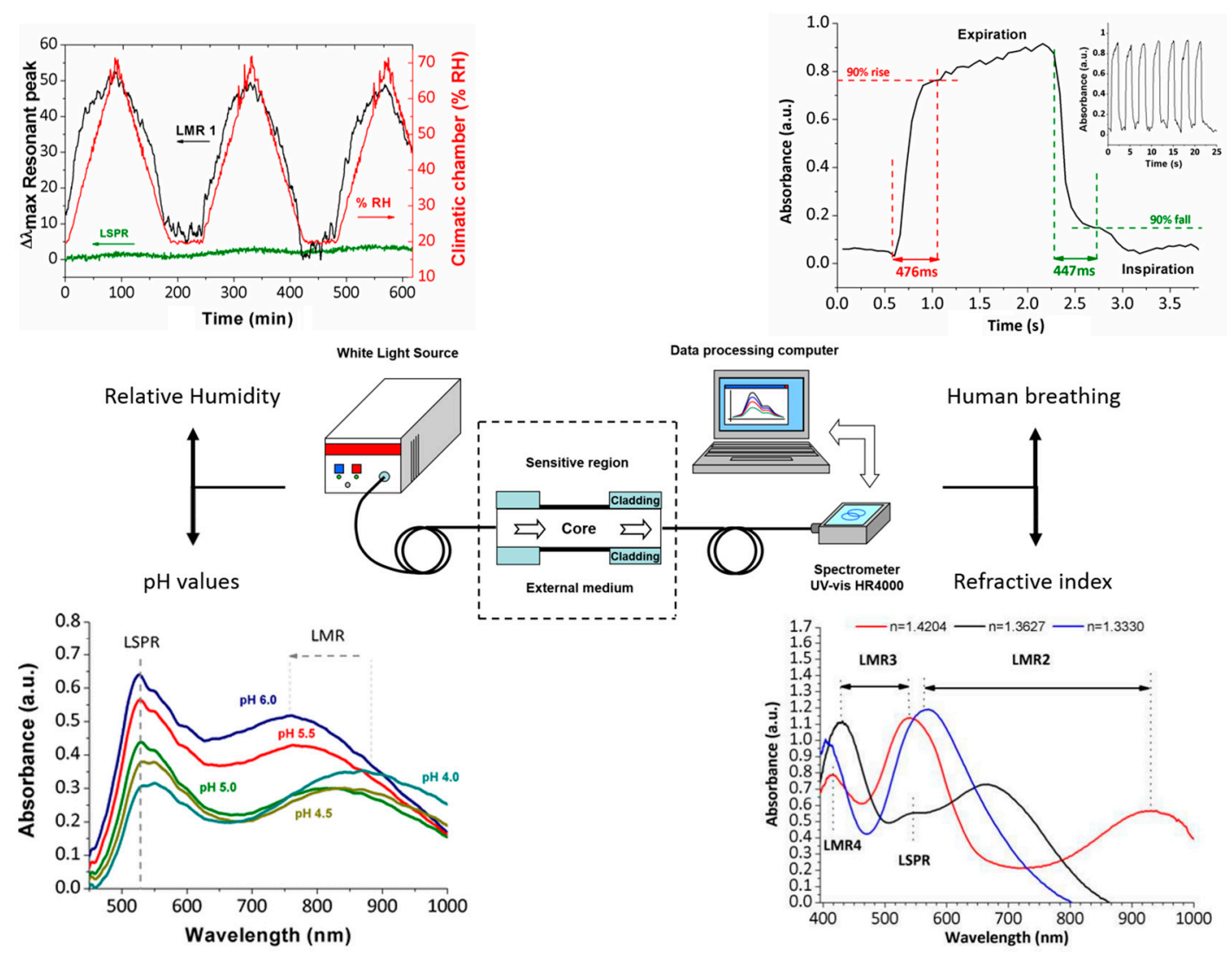

Figure 19. Experimental setup used for the design of dual LSPR-LMR optical fiber devices for sensing applications and the difference in their corresponding sensitivities in real cases for monitoring the Relative Humidity (RH), pH changes, human breathing and refractive index values.

A summary of the main applications of the optical fiber sensors evaluated in this work is presented in Table 5. Finally, it is necessary to remark that the presence of the metallic nanoparticles shows additional advantages in the nanostructured coatings. The first one is that these nanoparticles make possible an increase in the sensitivity of the device as well as an improvement in the visibility of the LMR bands for a thinner coating. In addition, the second one is that the presence of AgNPs allows an enhancement in the lifetime of the nanocoatings in high relative humidity environments due to its antibacterial behavior, whereas the presence of AuNPs makes possible a great biocompatibility for a further functionalization. 
Table 5. Summary of the main application of the optical fiber sensors based on sensitive nanocoatings.

\begin{tabular}{|c|c|}
\hline Deposition Technique & Sensing Parameter \\
\hline Layer-by-layer assembly & pH (range 4-7); Good repeatability and high sensitivity [114] \\
\hline Layer-by-layer assembly & $\begin{array}{l}\text { Fast and linear response in either acid or alkali solution ( } \mathrm{pH} \text { range } 2.5 \text { to 10); } \\
\text { Resolution of } 0.013 \mathrm{pH} \text { unit [115] }\end{array}$ \\
\hline Langmuir-Blodgett technique & Refractive index [116] \\
\hline $\begin{array}{l}\text { Radio-frequency plasma-enhanced } \\
\text { chemical-vapor-deposited } \operatorname{SiN}_{x} \text { nanocoating }\end{array}$ & Refractive index and temperature [117] \\
\hline Layer by-layer assembly & $\begin{array}{l}\text { High sensitivities of } 0.6 \mathrm{~nm} / \mathrm{pH} \text { unit and }-0.85 \mathrm{~nm} / \mathrm{pH} \text { unit for acidic and } \\
\text { alkaline solutions [119] }\end{array}$ \\
\hline Layer-by-layer assembly & $\begin{array}{c}\text { High accuracy of } \pm 0.001 \mathrm{pH} \text { units; Average sensitivity of } 0.027 \mathrm{pH} \text { units } / \mathrm{nm} \\
\text { (range between } \mathrm{pH}=3 \text { and } \mathrm{pH}=6 \text { ) [120] }\end{array}$ \\
\hline Layer-by-layer assembly & Refractive index and chemical species; Fast response time [121] \\
\hline Electrospinning & Gas sensing; High sensitivity and selectivity [122] \\
\hline Sol-gel technology; core-shell silica nanoparticles & Dissolved oxygen; High sensitivity [123] \\
\hline Layer-by-layer assembly & Relative Humidity [124] \\
\hline Layer-by-layer assembly & Relative Humidity and temperature [125] \\
\hline Layer-by-layer assembly & Refractive index [126] \\
\hline Sol-gel method & Hydrofluoric acid in aqueous solutions (137) \\
\hline Electrostatic self-assembly & LSPR sensing (gold nanospheres); DNA biosensor [138] \\
\hline Ionic self-assembled multilayers (ISAM) technique & LSPR sensing (gold nanoparticles); Biotin-streptavidin bioconjugate pair [139] \\
\hline Layer-by-layer assembly & LSPR sensing (gold nanoparticles); Antibody detection [140] \\
\hline Layer-by-layer assembly & LSPR and LMR sensing (silver nanoparticles); Relative humidity changes [144] \\
\hline Layer-by-layer assembly & LSPR and LMR sensing (gold nanoparticles); Refractive index changes [145] \\
\hline Layer-by-layer assembly & $\begin{array}{c}\text { LSPR and LMR sensing (gold nanorods); Refractive index and relative humidity } \\
\text { changes [146] }\end{array}$ \\
\hline Layer-by-layer assembly & LSPR and LMR sensing (gold nanorods); $\mathrm{pH}$ changes $[147,148]$ \\
\hline Layer-by-layer assembly & $\begin{array}{l}\text { LSPR and LMR sensing (silver nanoparticles); Human breathing and relative } \\
\text { humidity [149] }\end{array}$ \\
\hline
\end{tabular}

\section{Conclusions}

Wet chemistry coating technologies have proven to be easy to implement and scalable techniques to attain relevant goals in surface functionalization in fields such as high hydrophobicity, bacteriostaticity and sensorics.

The design of superhydrophobic surfaces for metallic alloys and fabrics has been successfully obtained by the sol-gel process involving hybrid or single silica matrices combined with water-repellent precursors. An appropriate texturing and roughening of surfaces on the nano and microscale is used to obtain these extreme wetting characteristics. The future outlook and open research lines in this specific field are associated with the design of bio-inspired special wettable surfaces which can be applied to a wide number of industrial applications such as finishing textile fabrics, corrosion resistance surfaces, self-cleaning properties, anti-graffiti surfaces, anti-icing or anti-snow coatings, among others.

Nanocoatings that present bactericide effects can be obtained by the incorporation of different types of nanoparticles (silver, copper, titanium oxide, zinc oxide) which are perfectly embedded in a single or hybrid matrix by using these wet-chemistry methods. In addition, the experimental results are better than those obtained by alternative physical techniques such as pulsed laser texturing. A future outlook for the design of textile fabrics with antibacterial behavior is focused on the development of multifunctional finishing properties such as photocatalytic activity, UV protection and long washing durability, making possible the fabrication of high value-added products. In order to obtain these multifunctional properties a good adhesion of the coating onto the textile fabrics by covalent bonds is necessary, the sol-gel technology being a good alternative.

Finally, the use of these nanofabrication techniques applied to the development of novel optical fiber sensors based on nanostructured coatings is a hot topic in the scientific community because they can present unique properties that can lead to important and significant advances in the design of 
novel optical devices. In this sense, sensing devices such as optical fiber can take advantage of these nanostructured materials in the implementation of improved sensors due to the intimate interactions of these nanostructures with a target parameter (i.e., $\mathrm{pH}$, gases, ions, volatile compounds, refractive index, and biomolecules) with a considerable enhancement in the resultant sensitivity. The detection of this wide variety of parameters makes possible their implementation in fields as diverse as aeronautics, food quality, environmental control, biomedicine or even in other industries.

Acknowledgments: This work was supported by the Spanish Economy and Competitiveness Ministry-FEDER Proyecto Retos TRA2013-48603-C4-1-R.

Conflicts of Interest: The authors declare no conflicts of interest.

\section{References}

1. Bell, T. Surface engineering: A rapidly developing discipline. Eur. J. Eng. Educ. 1987, 12, 27-32. [CrossRef]

2. Musil, J. Physical and mechanical properties of hard nanocomposite films prepared by reactive magnetron sputtering. In Nanostructured Coatings; Cavaleiro, A., de Hosson, J.T.M., Eds.; Springer: New York, NY, USA, 2006; pp. 407-463.

3. Shinn, M.; Hultman, L.; Barnett, S.A. Growth, structure, and microhardness of epitaxial TiN/NbN superlattices. J. Mater. Res. 1992, 7, 901-911. [CrossRef]

4. De Hosson, J.T.M.; Cavaleiro, A. Galileo comes to the surface! In Nanostructured Coatings; Springer: New York, NY, USA, 2006; pp. 1-26.

5. Decher, G. Fuzzy nanoassemblies: Toward layered polymeric multicomposites. Science 1997, 277, $1232-1237$. [CrossRef]

6. Izquierdo, A.; Ono, S.S.; Voegel, J.-C.; Schaaf, P.; Decher, G. Dipping versus spraying: Exploring the deposition conditions for speeding up layer-by-layer assembly. Langmuir 2005, 21, 7558-7567. [CrossRef] [PubMed]

7. Lavalle, P.; Gergely, C.; Cuisinier, F.J.G.; Decher, G.; Schaaf, P.; Voegel, J.C.; Picart, C. Comparison of the structure of polyelectrolyte multilayer films exhibiting a linear and an exponential growth regime: An in situ atomic force microscopy study. Macromolecules 2002, 35, 4458-4465. [CrossRef]

8. Choi, J.; Rubner, M.F. Influence of the degree of ionization on weak polyelectrolyte multilayer assembly. Macromolecules 2005, 38, 116-124. [CrossRef]

9. Shiratori, S.S.; Rubner, M.F. pH-dependent thickness behavior of sequentially adsorbed layers of weak polyelectrolytes. Macromolecules 2000, 33, 4213-4219. [CrossRef]

10. Yoo, D.; Shiratori, S.S.; Rubner, M.F. Controlling bilayer composition and surface wettability of sequentially adsorbed multilayers of weak polyelectrolytes. Macromolecules 1998, 31, 4309-4318. [CrossRef]

11. Derocher, J.P.; Mao, P.; Kim, J.Y.; Han, J.; Rubner, M.F.; Cohen, R.E. Layer-by-layer deposition of all-nanoparticle multilayers in confined geometries. ACS Appl. Mater. Interfaces 2012, 4, 391-396. [CrossRef] [PubMed]

12. Du, Y.; Luna, L.E.; Tan, W.S.; Rubner, M.F.; Cohen, R.E. Hollow silica nanoparticles in UV-Visible antireflection coatings for poly(methyl methacrylate) substrates. ACS Nano 2010, 4, 4308-4316. [CrossRef] [PubMed]

13. Nuraje, N.; Asmatulu, R.; Cohen, R.E.; Rubner, M.F. Durable antifog films from layer-by-layer molecularly blended hydrophilic polysaccharides. Langmuir 2011, 27, 782-791. [CrossRef] [PubMed]

14. Goicoechea, J.; Zamarreño, C.R.; Matías, I.R.; Arregui, F.J. Optical fiber pH sensors based on layer-by-layer electrostatic self-assembled neutral red. Sens. Actuators B Chem. 2008, 132, 305-311. [CrossRef]

15. Zamarreño, C.R.; Goicoechea, J.; Matías, I.R.; Arregui, F.J. Laterally selective adsorption of pH sensing coatings based on neutral red by means of the electric field directed layer-by-layer self-assembly method. Thin Solid Films 2009, 517, 3776-3780. [CrossRef]

16. Ki Bae, W.; Kwak, J.; Lim, J.; Lee, D.; Ki Nam, M.; Char, K.; Lee, C.; Lee, S. Multicolored light-emitting diodes based on all-quantum-dot multilayer films using layer-by-layer assembly method. Nano Lett. 2010, 10, 2368-2373. [CrossRef] [PubMed]

17. Xiao, F.-X.; Miao, J.; Liu, B. Layer-by-layer self-assembly of CdS quantum dots/graphene nanosheets hybrid films for photoelectrochemical and photocatalytic applications. J. Am. Chem. Soc. 2014, 136, 1559-1569. [CrossRef] [PubMed] 
18. Rivero, P.J.; Goicoechea, J.; Matias, I.R.; Arregui, F.J. A comparative study of two different approaches for the incorporation of silver nanoparticles into layer-by-layer films. Nanoscale Res. Lett. 2014, 9, 301. [CrossRef] [PubMed]

19. Rivero, P.J.; Goicoechea, J.; Urrutia, A.; Matias, I.R.; Arregui, F.J. Multicolor layer-by-layer films using weak polyelectrolyte assisted synthesis of silver nanoparticles. Nanoscale Res. Lett. 2013, 8, 438. [CrossRef] [PubMed]

20. Brinker, C.J.; Scherer, G.W. Sol-Gel Science: The Physics and Chemistry of Sol-Gel Processing; Academic Press: Cambridge, MA, USA, 2013.

21. Brinker, C.J.; Scherer, G.W. Sol $\rightarrow$ gel $\rightarrow$ glass: I. Gelation and gel structure. J. Non-Cryst. Solids 1985, 70, 301-322. [CrossRef]

22. Brinker, C.J.; Scherer, G.W.; Roth, E.P. Sol $\rightarrow$ gel $\rightarrow$ glass: II. Physical and structural evolution during constant heating rate experiments. J. Non-Cryst. Solids 1985, 72, 345-368. [CrossRef]

23. Scherer, G.W.; Brinker, C.J.; Roth, E.P. Sol $\rightarrow$ gel $\rightarrow$ glass: III. Viscous sintering. J. Non-Cryst. Solids 1985, 72, 369-389. [CrossRef]

24. Ying, J.Y.; Benziger, J.B. Structure tailoring of alkoxide silica. J. Non-Cryst. Solids 1992, 147, 222-231. [CrossRef]

25. Ying, J.Y.; Benziger, J.B.; Navrotsky, A. Structural evolution of colloidal silica gels to glass. J. Am. Ceram. Soc. 1993, 76, 2561-2570. [CrossRef]

26. Rivero, P.J.; Urrutia, A.; Goicoechea, J.; Zamarreño, C.R.; Arregui, F.J.; Matías, I.R. An antibacterial coating based on a polymer/sol-gel hybrid matrix loaded with silver nanoparticles. Nanoscale Res. Lett. 2011, 6, 305. [CrossRef] [PubMed]

27. Doshi, J.; Reneker, D.H. Electrospinning process and applications of electrospun fibers. J. Electrost. 1995, 35, 151-160. [CrossRef]

28. Burger, C.; Hsiao, B.S.; Chu, B. Nanofibrous materials and their applications. Ann. Rev. Mater. Res. 2006, 36, 333-368. [CrossRef]

29. Luo, C.J.; Stoyanov, S.D.; Stride, E.; Pelan, E.; Edirisinghe, M. Electrospinning versus fibre production methods: From specifics to technological convergence. Chem. Soc. Rev. 2012, 41, 4708-4735. [CrossRef] [PubMed]

30. Persano, L.; Camposeo, A.; Tekmen, C.; Pisignano, D. Industrial upscaling of electrospinning and applications of polymer nanofibers: A review. Macromol. Mater. Eng. 2013, 298, 504-520. [CrossRef]

31. Shabafrooz, V.; Mozafari, M.; Vashaee, D.; Tayebi, L. Electrospun nanofibers: From filtration membranes to highly specialized tissue engineering scaffolds. J. Nanosci. Nanotechnol. 2014, 14, 522-534. [CrossRef] [PubMed]

32. Zucchelli, A.; Focarete, M.L.; Gualandi, C.; Ramakrishna, S. Electrospun nanofibers for enhancing structural performance of composite materials. Polym. Adv. Technol. 2011, 22, 339-349. [CrossRef]

33. Deitzel, J.M.; Kleinmeyer, J.; Harris, D.; Beck Tan, N.C. The effect of processing variables on the morphology of electrospun nanofibers and textiles. Polymer 2001, 42, 261-272. [CrossRef]

34. Greiner, A.; Wendorff, J.H. Electrospinning: A Fascinating method for the preparation of ultrathin fibers. Angew. Chem. Int. Ed. 2007, 46, 5670-5703. [CrossRef] [PubMed]

35. Wang, X.; Drew, C.; Lee, S.-H.; Senecal, K.J.; Kumar, J.; Samuelson, L.A. Electrospun nanofibrous membranes for highly sensitive optical sensors. Nano Lett. 2002, 2, 1273-1275. [CrossRef]

36. Urrutia, A.; Goicoechea, J.; Rivero, P.J.; Matías, I.R.; Arregui, F.J. Electrospun nanofiber mats for evanescent optical fiber sensors. Sens. Actuators B Chem. 2013, 176, 569-576. [CrossRef]

37. Wang, X.; Drew, C.; Lee, S.-H.; Senecal, K.J.; Kumar, J.; Samuelson, L.A. Electrospinning technology: A novel approach to sensor application. J. Macromol. Sci. Pure Appl. Chem. 2002, 39, 1251-1258. [CrossRef]

38. Yao, X.; Song, Y.; Jiang, L. Applications of bio-inspired special wettable surfaces. Adv. Mater. 2011, 23, 719-734. [CrossRef] [PubMed]

39. Rivero, P.J.; Urrutia, A.; Goicoechea, J.; Arregui, F.J. Nanomaterials for functional textiles and fibers. Nanoscale Res. Lett. 2015, 10, 501. [CrossRef] [PubMed]

40. Lopez-Torres, D.; Elosua, C.; Hernaez, M.; Goicoechea, J.; Arregui, F.J. From superhydrophilic to superhydrophobic surfaces by means of polymeric layer-by-layer films. Appl. Surf. Sci. 2015, 351, 1081-1086. [CrossRef]

41. Gao, L.; McCarthy, T.J. “Artificial lotus leaf" prepared using a 1945 patent and a commercial textile. Langmuir 2006, 22, 5998-6000. [CrossRef] [PubMed] 
42. Gao, Q.; Zhu, Q.; Guo, Y.; Yang, C.Q. Formation of highly hydrophobic surfaces on cotton and polyester fabrics using silica sol nanoparticles and nonfluorinated alkylsilane. Ind. Eng. Chem. Res. 2009, 48, 9797-9803. [CrossRef]

43. Mazrouei-Sebdani, Z.; Khoddami, A. Alkaline hydrolysis: A facile method to manufacture superhydrophobic polyester fabric by fluorocarbon coating. Prog. Org. Coat. 2011, 72, 638-646. [CrossRef]

44. Wang, H.; Ding, J.; Xue, Y.; Wang, X.; Lin, T. Superhydrophobic fabrics from hybrid silica sol-gel coatings: Structural effect of precursors on wettability and washing durability. J. Mater. Res. 2010, 25, 1336-1343. [CrossRef]

45. Xu, L.; Shen, Y.; Wang, L.; Ding, Y.; Cai, Z. Preparation of vinyl silica-based organic/inorganic nanocomposites and superhydrophobic polyester surfaces from it. Colloid Polym. Sci. 2015, 293, $2359-2371$. [CrossRef]

46. Xu, L.; Cai, Z.; Shen, Y.; Wang, L.; Ding, Y. Facile preparation of superhydrophobic polyester surfaces with fluoropolymer $/ \mathrm{SiO}_{2}$ nanocomposites based on vinyl nanosilica hydrosols. J. Appl. Polym. Sci. $2014,131$. [CrossRef]

47. Berendjchi, A.; Khajavi, R.; Yazdanshenas, M.E. Fabrication of superhydrophobic and antibacterial surface on cotton fabric by doped silica-based sols with nanoparticles of copper. Nanoscale Res. Lett. 2011, 6, 594. [CrossRef] [PubMed]

48. Zheng, S.; Li, J. Inorganic-organic sol-gel hybrid coatings for corrosion protection of metals. J. Sol Gel Sci. Technol. 2010, 54, 174-187. [CrossRef]

49. Wang, D.; Bierwagen, G.P. Sol-gel coatings on metals for corrosion protection. Prog. Org. Coat. 2009, 64, 327-338. [CrossRef]

50. Poznyak, S.K.; Zheludkevich, M.L.; Raps, D.; Gammel, F.; Yasakau, K.A.; Ferreira, M.G.S. Preparation and corrosion protective properties of nanostructured titania-containing hybrid sol-gel coatings on AA2024. Prog. Org. Coat. 2008, 62, 226-235. [CrossRef]

51. Du, Y.J.; Damron, M.; Tang, G.; Zheng, H.; Chu, C.-J.; Osborne, J.H. Inorganic/organic hybrid coatings for aircraft aluminum alloy substrates. Prog. Org. Coat. 2001, 41, 226-232.

52. Cairns, D.R.; Kessman, A.J.; Richter, P.J.; Bottari, F.J.; Randall, N.X. Mechanical and tribological investigations of sol-gel derived $\mathrm{SiO}_{2}$ optical coatings. Wear 2008, 265, 411-416. [CrossRef]

53. Lakshmi, R.V.; Bharathidasan, T.; Basu, B.J. Superhydrophobic sol-gel nanocomposite coatings with enhanced hardness. Appl. Surf. Sci. 2011, 257, 10421-10426. [CrossRef]

54. Lakshmi, R.V.; Bera, P.; Anandan, C.; Basu, B.J. Effect of the size of silica nanoparticles on wettability and surface chemistry of sol-gel superhydrophobic and oleophobic nanocomposite coatings. Appl. Surf. Sci. 2014, 320, 780-786. [CrossRef]

55. Taurino, R.; Fabbri, E.; Pospiech, D.; Synytska, A.; Messori, M. Preparation of scratch resistant superhydrophobic hybrid coatings by sol-gel process. Prog. Org. Coat. 2014, 77, 1635-1641. [CrossRef]

56. Liang, J.; Hu, Y.; Wu, Y.; Chen, H. Facile formation of superhydrophobic silica-based surface on aluminum substrate with tetraethylorthosilicate and vinyltriethoxysilane as co-precursor and its corrosion resistant performance in corrosive $\mathrm{NaCl}$ aqueous solution. Surf. Coat. Technol. 2014, 240, 145-153. [CrossRef]

57. Wang, S.; Guo, X.; Xie, Y.; Liu, L.; Yang, H.; Zhu, R.; Gong, J.; Peng, L.; Ding, W. Preparation of superhydrophobic silica film on $\mathrm{Mg}-\mathrm{Nd}-\mathrm{Zn}-\mathrm{Zr}$ magnesium alloy with enhanced corrosion resistance by combining micro-arc oxidation and sol-gel method. Surf. Coat. Technol. 2012, 213, 192-201. [CrossRef]

58. Lai, D.; Kong, G.; Che, C. Synthesis and corrosion behavior of $\mathrm{ZnO} / \mathrm{SiO}_{2}$ nanorod-sub microtube superhydrophobic coating on zinc substrate. Surf. Coat. Technol. 2017, 315, 509-518. [CrossRef]

59. Yu, Q.; Xu, J. Structure and surface properties of fluorinated organic-inorganic hybrid films. J. Sol Gel Sci. Technol. 2012, 61, 243-248. [CrossRef]

60. Caldarelli, A.; Raimondo, M.; Veronesi, F.; Boveri, G.; Guarini, G. Sol-gel route for the building up of superhydrophobic nanostructured hybrid-coatings on copper surfaces. Surf. Coat. Technol. 2015, 276, 408-415. [CrossRef]

61. Liu, Y.; Chen, X.; Xin, J.H. Super-hydrophobic surfaces from a simple coating method: A bionic nanoengineering approach. Nanotechnology 2006, 17, 3259-3263. [CrossRef]

62. Isimjan, T.T.; Wang, T.; Rohani, S. A novel method to prepare superhydrophobic, uv resistance and anti-corrosion steel surface. Chem. Eng. J. 2012, 210, 182-187. [CrossRef] 
63. Maeztu, J.D.; Rivero, P.J.; Berlanga, C.; Bastidas, D.M.; Palacio, J.F.; Rodriguez, R. Effect of graphene oxide and fluorinated polymeric chains incorporated in a multilayered sol-gel nanocoating for the design of corrosion resistant and hydrophobic surfaces. Appl. Surf. Sci. 2017, 419, 138-149. [CrossRef]

64. Zheludkevich, M.L.; Serra, R.; Montemor, M.F.; Miranda Salvado, I.M.; Ferreira, M.G.S. Corrosion protective properties of nanostructured sol-gel hybrid coatings to AA2024-T3. Surf. Coat. Technol. 2006, 200, 3084-3094. [CrossRef]

65. Pepe, A.; Aparicio, M.; Ceré, S.; Durán, A. Preparation and characterization of cerium doped silica sol-gel coatings on glass and aluminum substrates. J. Non-Cryst. Solids 2004, 348, 162-171. [CrossRef]

66. Zaharescu, M.; Predoana, L.; Barau, A.; Raps, D.; Gammel, F.; Rosero-Navarro, N.C.; Castro, Y.; Durán, A.; Aparicio, $\mathrm{M}$. $\mathrm{SiO}_{2}$ based hybrid inorganic-organic films doped with $\mathrm{TiO}_{2}-\mathrm{CeO}_{2}$ nanoparticles for corrosion protection of AA2024 and Mg-AZ31B alloys. Corros. Sci. 2009, 51, 1998-2005. [CrossRef]

67. Liang, Y.; Wang, M.D.; Wang, C.; Feng, J.; Li, J.S.; Wang, L.J.; Fu, J.J. Facile synthesis of smart nanocontainers as key components for construction of self-healing coating with superhydrophobic surfaces. Nanoscale Res. Lett. 2016, 11, 231. [CrossRef] [PubMed]

68. Skorb, E.V.; Andreeva, D.V. Self-healing properties of layer-by-layer assembled multilayers. Polym. Int. 2015, 64, 713-723. [CrossRef]

69. Andreeva, D.V.; Fix, D.; Möhwald, H.; Shchukin, D.G. Self-healing anticorrosion coatings based on pH-sensitive polyelectrolyte/inhibitor sandwichlike nanostructures. Adv. Mater. 2008, 20, 2789-2794. [CrossRef] [PubMed]

70. Borodina, T.N.; Grigoriev, D.O.; Andreeva, D.V.; Möhwald, H.; Shchukin, D.G. Polyelectrolyte multilayered nanofilms as a novel approach for the protection of hydrogen storage materials. ACS Appl. Mater. Interfaces 2009, 1, 996-1001. [CrossRef] [PubMed]

71. Li, Y.; Li, L.; Sun, J. Bioinspired self-healing superhydrophobic coatings. Angew. Chem. Int. Ed. 2010, 49, 6129-6133. [CrossRef] [PubMed]

72. Manna, U.; Lynn, D.M. Restoration of superhydrophobicity in crushed polymer films by treatment with water: Self-healing and recovery of damaged topographic features aided by an unlikely source. Adv. Mater. 2013, 25, 5104-5108. [CrossRef] [PubMed]

73. Radwan, A.B.; Mohamed, A.M.A.; Abdullah, A.M.; Al-Maadeed, M.A. Corrosion protection of electrospun PVDF-ZnO superhydrophobic coating. Surf. Coat. Technol. 2016, 289, 136-143. [CrossRef]

74. Zhao, Y.; Xing, C.; Zhang, Z.; Yu, L. Superhydrophobic polyaniline/polystyrene micro/nanostructures as anticorrosion coatings. React. Funct. Polym. 2017, 119, 95-104. [CrossRef]

75. Zhao, Y.; Zhang, Z.; Yu, L.; Jiang, T. hydrophobic polystyrene/electro-spun polyaniline coatings for corrosion protection. Synth. Met. 2017, 234, 166-174. [CrossRef]

76. Zhao, Y.; Zhang, Z.; Yu, L. Corrosion protection of carbon steel by electrospun film containing polyaniline microfibers. React. Funct. Polym. 2016, 102, 20-26. [CrossRef]

77. Zhao, Y.; Zhang, Z.; Yu, L.; Tang, Q. Electrospinning of polyaniline microfibers for anticorrosion coatings: An avenue of enhancing anticorrosion behaviors. Synth. Met. 2016, 212, 84-90. [CrossRef]

78. Donlan, R.M.; Costerton, J.W. Biofilms: Survival mechanisms of clinically relevant microorganisms. Clin. Microbiol. Rev. 2002, 15, 167-193. [CrossRef] [PubMed]

79. Hajipour, M.J.; Fromm, K.M.; Akbar Ashkarran, A.; Jimenez de Aberasturi, D.; Larramendi, I.R.D.; Rojo, T.; Serpooshan, V.; Parak, W.J.; Mahmoudi, M. Antibacterial properties of nanoparticles. Trends Biotechnol. 2012, 30, 499-511. [CrossRef] [PubMed]

80. Mah, T.-F.C.; O'Toole, G.A. Mechanisms of biofilm resistance to antimicrobial agents. Trends Microbiol. 2001, 9, 34-39. [CrossRef]

81. Monteiro, D.R.; Gorup, L.F.; Takamiya, A.S.; Ruvollo-Filho, A.C.; Camargo, E.R.D.; Barbosa, D.B. The growing importance of materials that prevent microbial adhesion: antimicrobial effect of medical devices containing silver. Int. J. Antimicrob. Agents 2009, 34, 103-110. [CrossRef] [PubMed]

82. Rivero, P.J.; Urrutia, A.; Goicoechea, J.; Rodríguez, Y.; Corres, J.M.; Arregui, F.J.; Matías, I.R. An antibacterial submicron fiber mat with in situ synthesized silver nanoparticles. J. Appl. Polym. Sci. 2012, 126, 1228-1235. [CrossRef]

83. Falletta, E.; Bonini, M.; Fratini, E.; Lo Nostro, A.; Pesavento, G.; Becheri, A.; Lo Nostro, P.; Canton, P.; Baglioni, P. Clusters of poly(acrylates) and silver nanoparticles: structure and applications for antimicrobial fabrics. J. Phys. Chem. C 2008, 112, 11758-11766. [CrossRef] 
84. Timin, A.; Rumyantsev, E. Silver-Silica Nanocomposite materials incorporated into textile fabrics: Chemical and biological study. BioNanoScience 2013, 3, 415-422. [CrossRef]

85. Mahltig, B.; Fiedler, D.; Simon, P. Silver-containing sol-gel coatings on textiles: Antimicrobial effect as a function of curing treatment. J. Text. Inst. 2011, 102, 739-745. [CrossRef]

86. Mahltig, B.; Textor, T. Silver containing sol-gel coatings on polyamide fabrics as antimicrobial finish-description of a technical application process for wash permanent antimicrobial effect. Fibers Polym. 2010, 11, 1152-1158. [CrossRef]

87. Mihailovic, D.; Šaponjic, Z.; Vodnik, V.; Potkonjak, B.; Jovancic, P.; Nedeljkovic, J.M.; Radetic, M. Multifunctional PES fabrics modified with colloidal Ag and $\mathrm{TiO}_{2}$ nanoparticles. Polym. Adv. Technol. 2011, 22, 2244-2249. [CrossRef]

88. Radetic, M. Functionalization of textile materials with $\mathrm{TiO}_{2}$ nanoparticles. J. Photochem. Photobiol. C Photochem. Rev. 2013, 16, 62-76. [CrossRef]

89. Khurana, N.; Adivarekar, R.V. Effect of dispersing agents on synthesis of nano titanium oxide and its application for antimicrobial property. Fibers Polym. 2013, 14, 1094-1100. [CrossRef]

90. Azam, A.; Ahmed, A.S.; Oves, M.; Khan, M.S.; Habib, S.S.; Memic, A. Antimicrobial activity of metal oxide nanoparticles against gram-positive and gram-negative bacteria: A comparative Study. Int. J. Nanomed. 2012, 7, 6003-6009. [CrossRef] [PubMed]

91. Farouk, A.; Moussa, S.; Ulbricht, M.; Schollmeyer, E.; Textor, T. ZnO-modified hybrid polymers as an antibacterial finish for textiles. Text. Res. J. 2014, 84, 40-51. [CrossRef]

92. Mahltig, B.; Fiedler, D.; Böttcher, H. Antimicrobial sol-gel coatings. J. Sol Gel Sci. Technol. 2004, 32, $219-222$. [CrossRef]

93. Urrutia, A.; Rivero, P.J.; Ruete, L.; Goicoechea, J.; Fernández-Valdivieso, C.; Arregui, F.J.; Matías, I.R. An antibacterial surface coating composed of $\mathrm{PAH} / \mathrm{SiO}_{2}$ nanostructurated films by layer by layer. Phys. Status Solidi c 2010, 7, 2774-2777. [CrossRef]

94. Urrutia, A.; Rivero, P.J.; Ruete, L.; Goicoechea, J.; Matías, I.R.; Arregui, F.J. Single-stage in situ synthesis of silver nanoparticles in antibacterial self-assembled overlays. Colloid Polym. Sci. 2012, 290, 785-792. [CrossRef]

95. Whitehouse, J.D.; Friedman, N.D.; Kirkland, K.B.; Richardson, W.J.; Sexton, D.J. The impact of surgical-site infections following orthopedic surgery at a community hospital and a university hospital: Adverse quality of life, excess length of stay, and extra cost. Infect. Control Hosp. Epidemiol. 2002, 23, 183-189. [CrossRef] [PubMed]

96. Stoodley, P.; Ehrlich, G.D.; Sedghizadeh, P.P.; Hall-Stoodley, L.; Baratz, M.E.; Altman, D.T.; Sotereanos, N.G.; Costerton, J.W.; DeMeo, P. Orthopaedic biofilm infections. Curr. Orthop. Pract. 2011, 22, 558-563. [CrossRef] [PubMed]

97. Laverty, G.; Gorman, S.P.; Gilmore, B.F. Biomolecular mechanisms of staphylococcal biofilm formation. Future Microbiol. 2013, 8, 509-524. [CrossRef] [PubMed]

98. Foster, T.J.; Geoghegan, J.A.; Ganesh, V.K.; Höök, M. Adhesion, invasion and evasion: The many functions of the surface proteins of staphylococcus aureus. Nat. Rev. Microbiol. 2014, 12, 49-62. [CrossRef] [PubMed]

99. Romanò, C.L.; Scarponi, S.; Gallazzi, E.; Romanò, D.; Drago, L. Antibacterial coating of implants in orthopaedics and trauma: A classification proposal in an evolving panorama. J. Orthop. Surg. Res. 2015, 10, 157. [CrossRef] [PubMed]

100. Glinel, K.; Thebault, P.; Humblot, V.; Pradier, C.M.; Jouenne, T. Antibacterial surfaces developed from bio-inspired approaches. Acta Biomater. 2012, 8, 1670-1684. [CrossRef] [PubMed]

101. Ivanova, E.P.; Hasan, J.; Webb, H.K.; Gervinskas, G.; Juodkazis, S.; Truong, V.K.; Wu, A.H.F.; Lamb, R.N.; Baulin, V.A.; Watson, G.S.; et al. Bactericidal activity of black silicon. Nat. Commun. 2013, 4, 2838. [CrossRef] [PubMed]

102. Diu, T.; Faruqui, N.; Sjöström, T.; Lamarre, B.; Jenkinson, H.F.; Su, B.; Ryadnov, M.G. Cicada-inspired cell-instructive nanopatterned arrays. Sci. Rep. 2014, 4, 7122. [CrossRef] [PubMed]

103. Fadeeva, E.; Truong, V.K.; Stiesch, M.; Chichkov, B.N.; Crawford, R.J.; Wang, J.; Ivanova, E.P. Bacterial retention on superhydrophobic titanium surfaces fabricated by femtosecond laser ablation. Langmuir 2011, 27, 3012-3019. [CrossRef] [PubMed]

104. Valle, J.; Burgui, S.; Langheinrich, D.; Gil, C.; Solano, C.; Toledo-Arana, A.; Helbig, R.; Lasagni, A.; Lasa, I. Evaluation of surface microtopography engineered by direct laser interference for bacterial anti-biofouling. Macromol. Biosci. 2015, 15, 1060-1069. [CrossRef] [PubMed] 
105. Puckett, S.D.; Taylor, E.; Raimondo, T.; Webster, T.J. The relationship between the nanostructure of titanium surfaces and bacterial attachment. Biomaterials 2010, 31, 706-713. [CrossRef] [PubMed]

106. Ploux, L.; Anselme, K.; Dirani, A.; Ponche, A.; Soppera, O.; Roucoules, V. Opposite responses of cells and bacteria to micro/nanopatterned surfaces prepared by pulsed plasma polymerization and UV-irradiation. Langmuir 2009, 25, 8161-8169. [CrossRef] [PubMed]

107. Freschauf, L.R.; McLane, J.; Sharma, H.; Khine, M. Shrink-induced superhydrophobic and antibacterial surfaces in consumer plastics. PLoS ONE 2012, 7, e40987. [CrossRef] [PubMed]

108. Culshaw, B. Optical fiber sensor technologies: Opportunities and-perhaps-pitfalls. J. Light. Technol. 2004, 22, 39-50. [CrossRef]

109. Culshaw, B.; Kersey, A. Fiber-optic sensing: A historical perspective. J. Light. Technol. 2008, 26, $1064-1078$. [CrossRef]

110. Culshaw, B.; Stewart, G.; Dong, F.; Tandy, C.; Moodie, D. Fibre optic techniques for remote spectroscopic methane detection-From concept to system realisation. Sens. Actuators B Chem. 1998, 51, 25-37. [CrossRef]

111. Borisov, S.M.; Wolfbeis, O.S. Optical Biosensors. Chem. Rev. 2008, 108, 423-461. [CrossRef] [PubMed]

112. Oehme, I.; Wolfbeis, O.S. Optical sensors for determination of heavy metal ions. Mikrochim. Acta 1997, 126, 177-192. [CrossRef]

113. Corres, J.M.; Del Villar, I.; Matias, I.R.; Arregui, F.J. Two-layer nanocoatings in long-period fiber gratings for improved sensitivity of humidity sensors. IEEE Trans. Nanotechnol. 2008, 7, 394-400. [CrossRef]

114. Corres, J.M.; Matias, I.R.; del Villar, I.; Arregui, F.J. Design of pH sensors in long-period fiber gratings using polymeric nanocoatings. IEEE Sens. J. 2007, 7, 455-463. [CrossRef]

115. Gu, B.; Yin, M.-J.; Zhang, A.P.; Qian, J.-W.; He, S. Low-cost high-performance fiber-optic $\mathrm{pH}$ sensor based on thin-core fiber modal interferometer. Opt. Express 2009, 17, 22296-22302. [CrossRef] [PubMed]

116. Simões, E.; Abe, I.; Oliveira, J.; Frazão, O.; Caldas, P.; Pinto, J.L. Characterization of optical fiber long period grating refractometer with nanocoating. Sens. Actuators B Chem. 2011, 153, 335-339. [CrossRef]

117. Smietana, M.; Bock, W.J.; Mikulic, P. Temperature sensitivity of silicon nitride nanocoated long-period gratings working in various surrounding media. Meas. Sci. Technol. 2011, 22, 115203. [CrossRef]

118. Yarimaga, O.; Jaworski, J.; Yoon, B.; Kim, J.-M. Polydiacetylenes: Supramolecular smart materials with a structural hierarchy for sensing, imaging and display applications. Chem. Commun. 2012, 48, 2469-2485. [CrossRef] [PubMed]

119. Yin, M.; Gu, B.; Zhao, Q.; Qian, J.; Zhang, A.; An, Q.; He, S. Highly sensitive and fast responsive fiber-optic modal interferometric $\mathrm{pH}$ sensor based on polyelectrolyte complex and polyelectrolyte self-assembled nanocoating. Anal. Bioanal. Chem. 2011, 399, 3623-3631. [CrossRef] [PubMed]

120. Zamarreño, C.R.; Hernáez, M.; Del Villar, I.; Matías, I.R.; Arregui, F.J. Optical fiber pH sensor based on lossy-mode resonances by means of thin polymeric coatings. Sens. Actuators B Chem. 2011, 155, 290-297. [CrossRef]

121. Korposh, S.; James, S.W.; Lee, S.-W.; Topliss, S.; Cheung, S.C.; Batty, W.J.; Tatam, R.P. Fiber optic long period grating sensors with a nanoassembled mesoporous film of $\mathrm{SiO}_{2}$ nanoparticles. Opt. Express 2010, 18, 13227-13238. [CrossRef] [PubMed]

122. Yang, X.; Salles, V.; Kaneti, Y.V.; Liu, M.; Maillard, M.; Journet, C.; Jiang, X.; Brioude, A. Fabrication of highly sensitive gas sensor based on au functionalized $\mathrm{WO}_{3}$ composite nanofibers by electrospinning. Sens. Actuators B Chem. 2015, 220, 1112-1119. [CrossRef]

123. Chu, C.-S.; Lo, Y.-L. Optical fiber dissolved oxygen sensor based on $\mathrm{Pt}(\mathrm{II})$ complex and core-shell silica nanoparticles incorporated with sol-gel matrix. Sens. Actuators B Chem. 2010, 151, 83-89. [CrossRef]

124. Corres, J.M.; Matias, I.R.; Hernaez, M.; Bravo, J.; Arregui, F.J. Optical fiber humidity sensors using nanostructured coatings of $\mathrm{SiO}_{2}$ nanoparticles. IEEE Sens. J. 2008, 8, 281-285. [CrossRef]

125. Viegas, D.; Hernaez, M.; Goicoechea, J.; Santos, J.L.; Araújo, F.M.; Arregui, F.; Matias, I.R. Simultaneous measurement of humidity and temperature based on an $\mathrm{Sio}_{2}$-nanospheres film deposited on a long-period grating in-line with a fiber bragg grating. IEEE Sens. J. 2011, 11, 162-166. [CrossRef]

126. Hernáez, M.; Villar, I.D.; Zamarreño, C.R.; Arregui, F.J.; Matias, I.R. Optical fiber refractometers based on lossy mode resonances supported by $\mathrm{TiO}_{2}$ coatings. Appl. Opt. 2010, 49, 3980-3985. [CrossRef] [PubMed]

127. Liz-Marzán, L.M. Nanometals: Formation and color. Mater. Today 2004, 7, 26-31. [CrossRef] 
128. Liz-Marzán, L.M. Tailoring surface plasmons through the morphology and assembly of metal nanoparticles. Langmuir 2006, 22, 32-41. [CrossRef] [PubMed]

129. Rivero, P.J.; Goicoechea, J.; Urrutia, A.; Arregui, F.J. Effect of both protective and reducing agents in the synthesis of multicolor silver nanoparticles. Nanoscale Res. Lett. 2013, 8, 101. [CrossRef] [PubMed]

130. Elosua, C.; Arregui, F.J.; del Villar, I.; Ruiz-Zamarreño, C.; Corres, J.M.; Bariain, C.; Goicoechea, J.; Hernaez, M.; Rivero, P.J.; Socorro, A.B.; et al. Micro and nanostructured materials for the development of optical fibre sensors. Sensors 2017, 17, 2312. [CrossRef] [PubMed]

131. Lin, T.-J.; Chung, M.-F. Detection of cadmium by a fiber-optic biosensor based on localized surface plasmon resonance. Biosens. Bioelectron. 2009, 24, 1213-1218. [CrossRef] [PubMed]

132. Chau, L.-K.; Lin, Y.-F.; Cheng, S.-F.; Lin, T.-J. Fiber-optic chemical and biochemical probes based on localized surface plasmon resonance. Sens. Actuators B Chem. 2006, 113, 100-105. [CrossRef]

133. Lin, T.-J.; Chung, M.-F. Using monoclonal antibody to determine lead ions with a localized surface plasmon resonance fiber-optic biosensor. Sensors 2008, 8, 582-593. [CrossRef] [PubMed]

134. Mitsui, K.; Handa, Y.; Kajikawa, K. Optical fiber affinity biosensor based on localized surface plasmon resonance. Appl. Phys. Lett. 2004, 85, 4231-4233. [CrossRef]

135. Daniel, M.-C.; Astruc, D. Gold nanoparticles: assembly, supramolecular chemistry, quantum-size-related properties, and applications toward biology, catalysis, and nanotechnology. Chem. Rev. 2004, 104, 293-346. [CrossRef] [PubMed]

136. Lin, C.-A.J.; Yang, T.-Y.; Lee, C.-H.; Huang, S.H.; Sperling, R.A.; Zanella, M.; Li, J.K.; Shen, J.-L.; Wang, H.-H.; Yeh, H.-I.; et al. Synthesis, characterization, and bioconjugation of fluorescent gold nanoclusters toward biological labeling applications. ACS Nano 2009, 3, 395-401. [CrossRef] [PubMed]

137. Chen, I.-L.; Lin, S.-S.; Lin, T.-J.; Du, J.-K. Detection of hydrofluoric acid by a $\mathrm{SiO}_{2}$ sol-gel coating fiber-optic probe based on reflection-based localized surface plasmon resonance. Sensors 2011, 11, 1907-1923. [CrossRef] [PubMed]

138. Jia, S.; Bian, C.; Tong, J.-H.; Sun, J.-Z.; Xia, S.-H. A localized surface plasmon resonance DNA biosensor based on gold nanospheres coated on the tip of the fiber. Optoelectron. Lett. 2016, 12, 157-160. [CrossRef]

139. Wan, M.; Luo, P.; Jin, J.; Xing, J.; Wang, Z.; Wong, S.T.C. Fabrication of localized surface plasmon resonance fiber probes using ionic self-assembled gold nanoparticles. Sensors 2010, 10, 6477-6487. [CrossRef] [PubMed]

140. Shao, Y.; Xu, S.; Zheng, X.; Wang, Y.; Xu, W. Optical fiber LSPR biosensor prepared by gold nanoparticle assembly on polyelectrolyte multilayer. Sensors 2010, 10, 3585-3596. [CrossRef] [PubMed]

141. Budy, S.M.; Hamilton, D.J.; Cai, Y.; Knowles, M.K.; Reed, S.M. Polymer mediated layer-by-layer assembly of different shaped gold nanoparticles. J. Colloid Interface Sci. 2017, 487, 336-347. [CrossRef] [PubMed]

142. Fu, Y.; Xu, H.; Bai, S.; Qiu, D.; Sun, J.; Wang, Z.; Zhang, X. Fabrication of a stable polyelectrolyte/Au nanoparticles multilayer film. Macromol. Rapid Commun. 2002, 23, 256-259. [CrossRef]

143. Malikova, N.; Pastoriza-Santos, I.; Schierhorn, M.; Kotov, N.A.; Liz-Marzán, L.M. Layer-by-layer assembled mixed spherical and planar gold nanoparticles: control of interparticle interactions. Langmuir 2002, 18, 3694-3697. [CrossRef]

144. Rivero, P.J.; Urrutia, A.; Goicoechea, J.; Arregui, F.J. Optical fiber humidity sensors based on localized surface plasmon resonance (LSPR) and lossy-mode resonance (LMR) in overlays loaded with silver nanoparticles. Sens. Actuators B Chem. 2012, 173, 244-249. [CrossRef]

145. Rivero, P.J.; Hernaez, M.; Goicoechea, J.; Matias, I.R.; Arregui, F.J. Optical fiber refractometers based on localized surface plasmon resonance (LSPR) and lossy mode resonance (LMR). In 23rd International Conference on Optical Fibre Sensors, Proceedings of OFS2014 23rd International Conference on Optical Fiber Sensors, Santander, Spain, 2-6 June 2014; López-Higuera, J.M., Jones, J.D.C., López-Amo, M., Santos, J.L., Eds.; SPIE: Bellingham, WA, USA, 2014.

146. Urrutia, A.; Goicoechea, J.; Rivero, P.J.; Pildain, A.; Arregui, F.J. Optical fiber sensors based on gold nanorods embedded in polymeric thin films. Sens. Actuators B Chem. 2018, 255, 2105-2112. [CrossRef]

147. Rivero, P.J.; Goicoechea, J.; Hernaez, M.; Socorro, A.B.; Matias, I.R.; Arregui, F.J. Optical fiber resonance-based $\mathrm{pH}$ sensors using gold nanoparticles into polymeric layer-by-layer coatings. Microsyst. Technol. 2016, 22, 1821-1829. [CrossRef] 
148. Socorro, A.B.; Rivero, P.J.; Hernaez, M.; Goicoechea, J.; Matias, I.R.; Arregui, F.J. Optical fiber pH sensor based on gold nanoparticles into polymeric coatings. In Smart Sensors, Actuators, and MEMS VII; and Cyber Physical Systems, Proceedings of SPIE Microtechnologies, Barcelona, Spain, 8-10 May 2015; Sánchez-Rojas, J.L., Brama, R., Eds.; SPIE: Bellingham, WA, USA, 2014.

149. Rivero, P.J.; Urrutia, A.; Goicoechea, J.; Matias, I.R.; Arregui, F.J. A lossy mode resonance optical sensor using silver nanoparticles-loaded films for monitoring human breathing. Sens. Actuators B Chem. 2013, 187, 40-44. [CrossRef]

150. Del Villar, I.; Zamarreño, C.R.; Hernaez, M.; Arregui, F.J.; Matias, I.R. Generation of lossy mode resonances with absorbing thin-films. J. Light. Technol. 2010, 28, 3351-3357. [CrossRef]

(C) 2018 by the authors. Licensee MDPI, Basel, Switzerland. This article is an open access article distributed under the terms and conditions of the Creative Commons Attribution (CC BY) license (http://creativecommons.org/licenses/by/4.0/). 